University of Louisville

ThinkIR: The University of Louisville's Institutional Repository

Electronic Theses and Dissertations

$12-2006$

\title{
Gary Snyder's idiosyncratic Buddhist poetics and the "razoredge".
}

David Gerhardt Thimme 1970-

University of Louisville

Follow this and additional works at: https://ir.library.louisville.edu/etd

\section{Recommended Citation}

Thimme, David Gerhardt 1970-, "Gary Snyder's idiosyncratic Buddhist poetics and the "razoredge"." (2006). Electronic Theses and Dissertations. Paper 1428.

https://doi.org/10.18297/etd/1428

This Master's Thesis is brought to you for free and open access by ThinkIR: The University of Louisville's Institutional Repository. It has been accepted for inclusion in Electronic Theses and Dissertations by an authorized administrator of ThinkIR: The University of Louisville's Institutional Repository. This title appears here courtesy of the author, who has retained all other copyrights. For more information, please contact thinkir@louisville.edu. 


\title{
GARY SNYDER'S IDIOSYNCRATIC BUDDHIST'POETICS AND THE "RAZOREDGE”
}

\author{
By
}

David Gerhardt Thimme

B.S., Bradley University, 1993

Main Advisor

Dr. Aaron Jaffe

\author{
A Thesis \\ Submitted to the Faculty of the \\ Graduate School of the University of Louisville \\ in Partial Fulfillment of the Requirements \\ for the Degree of
}

Master of Arts

Department of English University of Louisville Louisville, Kentucky

December 2006 


\section{GARY SNYDER'S IDIOSYNCRATIC BUDDHIST POETICS}

AND THE “RAZOREDGE”

$$
\text { By }
$$

David Gerhardt Thimme

M.A., Louisville, 2006

A Thesis Approved on

November 21, 2006

by the following Thesis Committee:

Thesis Director 


\section{ACKNOWLEDGMENTS}

I would like to thank my main advisor and friend, Dr. Aaron Jaffe, for his excellent guidance during this long journey of discovery. I would also like to thank the

other committee members, Dr. Thomas Byers and Dr. Mary Ann Stenger, for devoting their time and knowledge to a project that I am so deeply passionate about. Your feedback enabled me to greatly enhance the final version of this thesis.

Thank you to my parents, Jerry and Jane Thimme, for their unwavering support that dates back to my "non-verbal" experience of the world. Thanks to my son, Ethan Thimme - you show me the fullness of the 'present moment' every day! Most importantly, thank you to my wife, Ellen Thimme. Without you, none of this investigating of the ineffable would be possible. 


\section{ABSTRACT \\ GARY SNYDER'S IDIOSYNCRATIC BUDDHIST POETICS AND THE "RAZOREDGE" \\ David Gerhardt Thimme}

December 14, 2006

Gary Snyder's poetry conveys Zen states of consciousness through unconventional grammar and syntax. From his first book Riprap in 1959 to his last collection of poems, Mountains and Rivers Without End in 1996, he has confronted the challenge of transforming Buddhist philosophy and discourse into Western poetics. Snyder's syncretism pertaining to Buddhist and Native American beliefs form a unique view of Zen that suggests his precise involvement with the meditative self-discipline may be unstable and elusive. A close reading of Snyder's idiosyncratic Buddhist poetics reveals an impasse between a "non-verbal" realm, where the Cartesian duality of subject and object dissolves, and the Western outlook that consciousness can't escape language and thought; Snyder's term "razoredge" corresponds to this juncture. Viewing his works from a Buddhist perspective, which emphasizes Eastern forms such as haiku and the Zen koan, shows how the disruption of ordinary "dualistic" thinking potentially improves the aesthetic of "nonduality." 


\section{TABLE OF CONTENTS}

PAGE

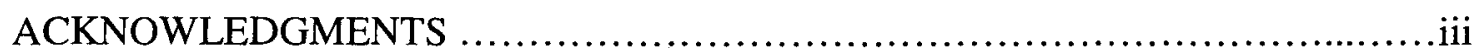

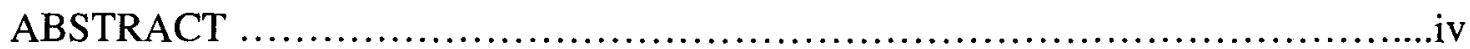

\section{CHAPTER}

\section{INTRODUCTION}

What is Zen? ........................................................ 3

"Non-verbal" Perception .........................................6

Transcendentalism: Emerson, Thoreau, and Whitman ..................9

Imagism and Modernism: Fenollosa, Pound, and Williams .............11

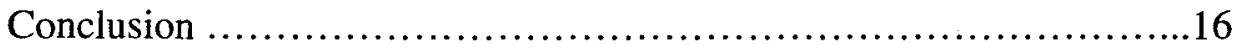

II. THE "RAZOREDGE" BETWEEN EAST AND WEST

Introduction ........................................................

A Buddhist Perspective on "Sixth-Month Song in the Foothills" ........20

Differentiating "Zen Mind” from a "Dualistic" Mind....................27

The "Poetics of Presence" .............................................

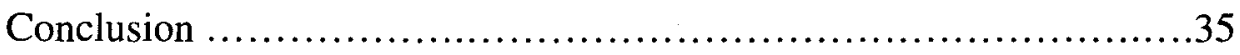

III. MENDING THE FRACTURED IDENTITY IN "PIUTE CREEK"

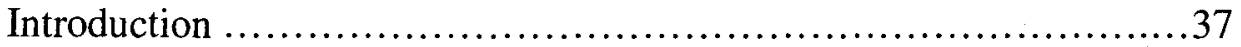

A Buddhist Perspective on "Piute Creek" ...............................39 
Tim Dean's Reading of the Coyote

Allusion to Dōgen's Enlightenment ...................................45

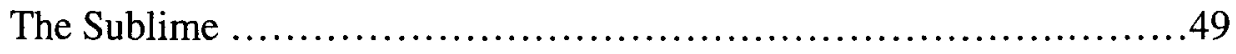

Snyder and the Transcendentalists ................................52

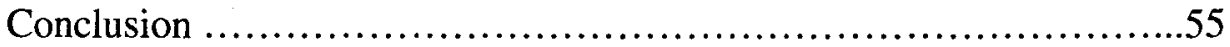

\section{BRINGING THE EAST TO THE WEST THROUGH 'DISRUPTION'}

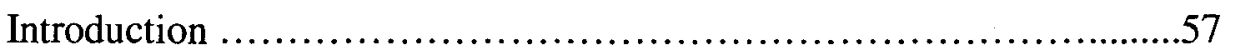

Riprap / Myths and Texts .........................................58

A Buddhist Perspective on "Finding the Space in the Heart" ..............61

Gary Snyder and Deconstructionist Jacques Derrida .....................70

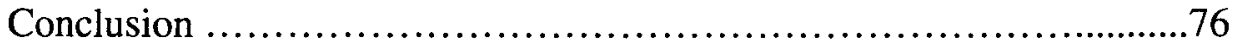

\section{EPILOGUE: ACCEPTING 'RESISTANCE TO INTERPRETATION'}

"Finding the Space in the Heart" and Postmodernism ....................78

Nagarjuna's Logic and Postmodernism ........................................81

Embracing 'Resistance to Interpretation' .............................82

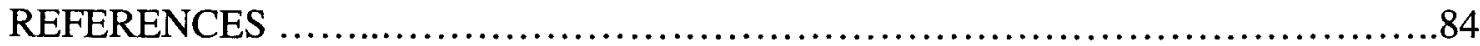

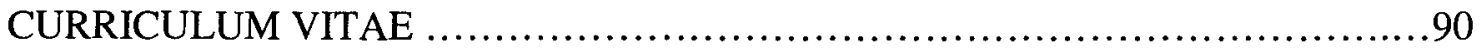




\section{CHAPTER I}

\section{INTRODUCTION}

The title of Gary Snyder's fourth book, Earth House Hold: Technical Notes \& Queries to Fellow Dharma Revolutionaries, was published in 1969 and communicates the depth of his involvement with Zen practice and Buddhist philosophy (Dean xv). The book consists primarily of journal entries and prose from his first trip to Japan in 1956 (xiv). In Snyder's three books prior to Earth, he cultivates a poetic style and form that expresses a holistic perspective, which puts animals and plants on the same plane as humans. His exceptional ability to blur the boundary between the small and infinite in nature, distinguishes his poetry from "American nature writing" contemporaries and predecessors. The most significant element of Snyder's poetics, which differentiates him from other poets, is the influence of Zen studies and practice on his poetry.

For over four decades, Snyder's sensitivity to the outer world through a developing inner awareness has served as the predicate for portraying Zen states of consciousness. One of the greatest challenges facing Snyder is the task of transforming Buddhist philosophy and discourse into images and ideas that convey concepts such as "nonduality," "no self," and "interdependence." His willingness to confront highly metaphysical aspects of Buddhist philosophy is complicated by a diverse set of cultural influences, including Native American mythology, Chinese scroll painting, Chinese and 
Japanese poetry, primitive and ancient societies, Taoism, and Buddhist culture. Rather than limit his poetry and prose to one sphere of Buddhism, he takes advantage of the religion's rich history and mythology, as well as the tremendous flexibility of Buddhist philosophy. Furthermore, to express his radical eco-politics and Buddhist values, Snyder embraces the public sphere through interviews and essays. In his essay "A Passage to More than India" from Earth, Snyder's view of Vajrayana Buddhism as "probably the finest and most modern statement of this ancient shamanistic-yogic-gnosticsocioeconomic view: that mankind's mother is Nature and Nature should be tenderly respected," suggests his precise involvement with the religion may be unstable and elusive (105).

His mastery of translating Chinese and Japanese poetic forms, steadfast devotion to Zen practice, and immersion in the art forms of the East, unite to form a unique body of work that cannot be reduced to "American nature writing." However, the combination of Snyder's immersion in Eastern culture, expertise in contemporary Western poetics, and an indeterminable degree of insight into Zen states of consciousness, leads to frequent contradictions in his writings. In order to counter these inconsistencies in his poetry, Snyder draws on his Zen insights surrounding the complex relationship between silence and language. His perspective, which integrates Eastern and Western poetics, leads to an extremely creative poetics. When my analysis reveals unique tactics and techniques for expressing Buddhist philosophy and discourse, I will use the phrase "idiosyncratic Buddhist poetics" to designate Snyder's innovative methods.

This thesis examines Gary Snyder's use of grammar, rhetorical devices, and unconventional strategies for conveying Zen states of consciousness, particularly the 
realization of the Void. One purpose is to determine whether readers can absorb the complex ideas that he communicates by transforming the aesthetics of Eastern poetry, as well as his own poetic inventions, into various forms of Western contemporary poetics. Chapters two through four each include a close reading of one of Snyder's poems. Then, the chapters explore the tensions in a larger discussion that involves the relationship between "pure presence" as a symbol of the East and the skepticism that it faces from postmodern thought in Western culture. The overarching aim of this thesis is to address the impasse that results when Snyder's idiosyncratic Buddhist poetics coincides with literary models and philosophy of the East and West.

\section{What is Zen?}

During Snyder's first year at Reed College in the late 1940's, his roommate Philip Whalen introduced him to Zen (Steuding 17). Given the unfamiliarity of the term in America at the time, the question "What is Zen?" would have likely led to many more questions. The term refers to a type of Mahayana Buddhist practice that originated in China in the sixth century CE and spread to Japan less than four decades later (Diener, et al 34-35). A short time after Buddha's death in $483 \mathrm{BC}$, disagreement surfaced over the meanings of his teachings and the best method for attaining enlightenment. The two most important Zen schools are Rinzai and Soto, the former stresses the koan and attending to daily work, as opposed to the long, rigorous sitting meditation (zazen) emphasized by the latter (Disanto, Steele 128-130). The growth of Zen throughout the world has led to the formation of numerous schools, each with their own unique approach to meditative self-discipline designed to actualize "the perfection present in every person 
at every moment" (Diener, et al 263). A common aim for the Zen practitioner is "enlightenment by direct intuition through meditation" ("Zen"). Anyone can practice Zen, but few attain enlightenment. This profound experience entails the realization of the Void, or "emptiness" - known also by the Sanskrit term śünyatā. The Shambhala Dictionary states that when enlightenment occurs, "A person awakens to the nowness of emptiness... which he himself is-even as the entire universe is emptiness-and which alone enables him to comprehend the true nature of things" (Diener, et al 65). Zen and Buddhist discourse such as this infuses nearly all definitions of enlightenment and is echoed throughout Snyder's prose and poetry. A more rudimentary notion of Zen that is encompassed by the Void is an immediate understanding of things "as they are in themselves" (Crittenden 52).

Buddhism and Zen are inextricably connected, but the former relates to the hundreds of schools and multitude of texts that derive from the teachings of Buddha. The beliefs, texts, and traditions that stem from Buddha's search for a higher truth, escape from the inherent suffering of life, and explanation of the cycle of birth and death, validate Buddhism's status as a religion (Diener, et al 32). In contrast, most forms of Zen do not uphold a particular scripture and emphasize the experience of "direct intuition" rather than a belief system (Diener, et al 261-262). Zen philosophers are infamous for their non-rational paradoxical approach to metaphysical questions. Although Buddhism and Zen are often used interchangeably, I will use the general classifications above as a guide for differentiating between the terms Buddhism and Zen. When the difference appears ambiguous, I will defer to the term Buddhism because it reaches back to the unique culture where Zen originates. Although the Americanization of Buddhism and 
Zen flourished in the 1960s, even today, there is little agreement in the West about the ways in which meditation and contemplation influence one's thinking and behavior. As a result, the term Zen can be categorized as both a philosophy and religion.

Snyder's shaping of unique states of consciousness like enlightenment and the Void can be mapped throughout his extensive collection of poetry and prose. The Zen notion of transcending the "self" and liberating the mind from "dualistic" thinking resonates in his writing. His unwavering devotion to Zen also grounds his radical ethical stance involving humanity and nature. However, although his political views appear unambiguous, gauging the depth of his experience with Zen states of consciousness proves to be a precarious pursuit. Snyder reinforces the mystery of his authenticity as a Buddhist guru when he reticently expresses a profound realization, which closely resembles enlightenment:

I don't lay claim to any great enlightenment experiences or anything like that, but I have had a very moving, profound perception a few times that everything was alive (the basic perception of animism) and that on one level there is no hierarchy of qualities in life-that the life of a stone or a weed is as completely beautiful and authentic, wise and valuable as the life of, say, an Einstein. (Real Work 17)

Although Snyder's remarks about enlightenment are conditional and inconclusive, the passage leaves open the possibility of "direct intuition." Throughout the 1950's and 1960's, Snyder spent nearly a decade in Japan studying Rinzai Zen. The Rinzai tradition believes that an "enlightenment experience" can occur "in an instant and can come at any time, e.g. in the midst of all sorts of everyday activities, such as chopping wood" 
(Disanto, Steele 130). Snyder's Rinzai Zen studies in Japan amounted to less than two years when he first depicted enlightenment and the Void in Riprap. Consequently, his knowledge of these states is the source of considerable speculation from literary critics, many specializing in Buddhism.

\section{“Non-verbal” Perception}

Though the concepts of enlightenment and the Void vary across different schools of Buddhism, they are predominantly centered around a "non-verbal" or "non-linguistic" perception. Ruth Fuller Sasaki, known as the "mother of American Buddhism" and a mentor to Snyder, depicts the profound awareness as "a nonconceptual, ineffable awareness ... which has as its aim the bringing of the student to direct, intuitive realization of reality without recourse to the mediation of words or concepts" (Heine, Wright 8 ). His most ambitious poetry seeks to bring the reader to the brink of "what can be said and that which cannot be said" (Real Work 21). In Earth, Snyder refers to this threshold as the "razoredge" (41).

One of the primary realizations of a "non-verbal" experience is "no self," or the dissolving of the subject/object construct of the "self." Dale Wright, author of Philosophical Meditations on Zen Buddhism, defines the term by stating: "Like everything else, we are embedded in the world; we are immersed in an infinitely interconnected context in such a way that 'self' and 'other' interpenetrate" (52-53). Seeing the world without the usual boundaries that separate binaries like "self" and "other" is known in Buddhism as "nonduality" (53). In Earth, Snyder denotes this perception, which arises with a Zen state of consciousness, when he writes: 
Almost had it last night: no identity. One thinks, "I emerged from some general, non-differentiated thing, I return to it." One has in reality never left it; there is no return.

my language fades. Images of erosion. (10)

The articulation of "no self" grows more complex when the "non-verbal" or "nonconceptual" perception fails to equate to the Western idea of 'pure objectivity.' The problem arises because the latter term cannot be formed without producing a dichotomous relationship with subjectivity and turning 'pure objectivity' into an "absolute." This theory violates the idea that ordinary "dualistic" thinking has dissolved (Ives 46). In his poetry and through his public remarks, Snyder confronts these idiosyncratic properties of language that arise when conveying Buddhist philosophy. By approaching three of his poems from a Buddhist perspective, I aim to probe the "unsettling depths" of his poetics (Riprap 67).

Although "direct intuition," such as the perception of "no self," occurs only in the prepared mind, Snyder incorporates Eastern forms and aesthetics into his poetry to more effectively convey Zen states of consciousness. Both haiku and the koan are known for bringing about enlightenment through language and silence. Early in his career, Snyder's remarks reveal a fascination with how close a Western reader can come to a genuine "awakening." He points to the importance of having his poetry steer a "course between crystal clouds of utterly incommunicable non-verbal states—and the gleaming daggers and glittering nets of language" (Snyder, Earth 118). In the same book, he clarifies the distinction between the "non-verbal" and verbal realms from a more intellectual perspective:

A poet sort of faces two directions: one is to the world of people and language and society, and the tools by which he communicates his 
language; and the other is the non-human, non-verbal world ... before language, before custom, before culture. There's no words in that realm.

This gap between silence and language is extremely significant because it touches on the challenge of conveying the Void. Literary critic Robert Kern comments on Snyder's ambitious goal of bringing readers to the "razoredge" and the limits of language to handle the task. He writes, "Such knowledge for Snyder is apprehended in an existential act of perception prior to poetic composition which the poem can later dramatize and reflect" (“Clearing" 167). His observation portrays a poet seemingly resigned to communicate a mediated reality. However, the critical tone in the above passage is missing in the following sentence from Riprap: "There is also the work of seeing the world without any prism of language, and to bring that seeing into language" (67). Furthermore, in Myths and Texts, his second published book, he boldly declares his intention to create poetry that acts as "a riprap on the slick rock of metaphysics" (43). The slickest point of Buddhist metaphysics is the Void; chapters three and four focus on Snyder's shaping of śünyatō.

The elusiveness of Zen and Snyder's poetics complicates any effort to determine the degree to which Zen states of consciousness can be apprehended or experienced by a reader. This thesis contrasts the application of Western literary and philosophical models with Buddhist philosophy and discourse in order to explore the "non-verbal" realm in three of Snyder's poems. To break through the impasse between Eastern and Western models, I approach his texts from a Buddhist perspective that includes the influence of haiku and the Zen koan. 


\section{Transcendentalism: Emerson, Thoreau, and Whitman}

Whenever Snyder portrays a Zen state of consciousness, nature always acts as a mirror for the movement of his mind. His tremendous ability to blur the boundary between the small and infinite in nature creates an "aesthetic of neutrality" in relation to the nonhuman world. This skill links him with the American Transcendentalists. As Bob Murphy writes in his book Understanding Gary Snyder, Snyder read Thoreau's Walden when he was about nineteen (2). The former pays homage to Walden by taking the line "The sun is but a morning star" from the famous text, and making it the last verse of his first completed book, Myths and Texts (48). Although Snyder is characterized as an heir to "American nature writing," his style and representation of visionary moments in nature differ in important ways from the writings of the Transcendentalists.

Like Emerson and Thoreau, Snyder cultivated a moral status that stems from his reverence for nature. However, unlike his Transcendentalist predecessors, Snyder devoted his life to the practice of Zen in order to satisfy deep spiritual aspirations. Emerson and Thoreau absorbed Eastern religious ideas primarily to enhance their nature writing and philosophical outlook. Their desire for self realization within the Western religious framework instilled in their writing varying degrees of anthropocentrism. The two forefathers of Transcendentalism viewed nature as the source from which visions of the divine could be reached.

As I will show in chapter two, Snyder attempts to convey a Zen state of consciousness that stresses transcendence of the "self" and an aesthetic of neutrality among human and non-human life forms. This nature poetry diverges from the Transcendentalists writing, which frequently leads to an appropriation of nature. 
Although the writings of Emerson and Thoreau frequently mirror Eastern religion, the intrusion of their subjectivity, and presence of Western religion's conception of God, result in a pronounced anthropocentrism. One of the challenges facing Snyder is to avoid the techniques of Emerson and Thoreau which lead to a self-centered mystical experience. In an interview with Paul Geneson in 1976, Snyder stresses that Zen has helped him find the "right path," which involves "exploration of consciousness itself: self-understanding, transcendence of self" (Snyder, Real Work 68). The aesthetic of transcending the "self" counters the Transcendentalist model where the subject abandons the ground for "transcendental elevation" (Dean 36).

For the American transcendentalists and Snyder, the natural environment is transfigured into a mythic space where individuals can find their true selves. This romanticized view of America has led literary critics to argue that their poetry displaces anxieties about the relation between land and identity. Literary critic Tim Dean pinpoints rugged individualism as part of their motivation for venturing into the wild (86-87). This theme is consistent with the Transcendentalists' ego-minded adherence to individual experience, but conflicts with the perception of Snyder as the altruistic spokesman for the wilderness. Snyder distinguishes his poetics from his predecessors through several creative strategies, which include growing the perception of an equiniminous relationship with nature. He states, "I've recently come to realize that the rhythms of my poems follow the rhythm of the physical work I'm doing and the life I'm leading at any given time" (Bly 357). He further narrows the gap between humans and nature when he states, "riprap is really a class of poems I wrote under the influence of the geology of the Sierra Nevada and the daily trail-crew work of picking up and placing granite stones in tight 
cobble patterns on hard slab" (357). Snyder's poetics, and the Zen outlook they reflect, dispute the idea that selfish desire is the primary motivation for his immersion in nature. By combining Zen's focus on meditation and contemplation with physical labor, Snyder neutralizes his speaker's subjectivity and creates a non-transcendental tone that diminishes anthropocentrism in his poetry. Dean notes a similarity between Whitman's Leaves of Grass and Snyder's Riprap, in which the "self" is portrayed "as natural man, man in Nature working (not man in Nature meditating on himself as a transparent eyeball or as the centre of natural relations)" (87). Just as Whitman declared himself "one of the roughs," Snyder dedicates Riprap to his trail-crew and the men he shared time with at Sea (87). However, Whitman's overt subjectivity and anthropocentrism link him with the unconcealed ego-mindedness of the Transcendentalists. Moreover, Snyder permanently resides in the wild and his writings reflect the Zen belief in making "your work your meditation" (Norton 171). This approach deviates from Whitman and Emerson's predilection for cataloguing nature's objects and Thoreau's use of science in his writings, all of which mediate nature for the reader and frequently lead to self-dramatized experiences.

\section{Imagism and Modernism: Fenollosa, Pound, and Williams}

The poems in Riprap express the meditative quality of work and generally resonate with a tone of stillness and stability. This impression creates an ideal backdrop for neutralizing the speaker's subjectivity and conveying the substantive meaning of an object. Much of the stylistics from Snyder's early poetry reaches back to the Imagist movement that began during the early years of the twentieth century, and whose chief 
representative was Ezra Pound. Imagism is characterized by a distrust of abstractions and, as the name implies, the poetry from that period was devoted to "[d]irect treatment of the 'thing' whether subjective or objective" (Jones 124). As a reaction to the dominant style of decorative verse exemplified by British poet Rudyard Kipling, one of Pound's central tenets was: "To use absolutely no word that did not contribute to the presentation" (124). Snyder's use of the short form of Chinese and Japanese poetry reflects the influence of Pound's Imagist style. The former's works include an abundance of haikulike poems, and the words, with their "monosyllabic step-by-step placement, their crispness" embody the poetic qualities of Imagism (Snyder Riprap, 66). Finally, Snyder's use of free verse serves an ideal form for unconventional grammatical strategies that fit the Imagist aesthetic.

Imagism eventually merged with the larger modernist movement which dates from approximately 1915 to 1945 (O'Conner). Pound and William Carlos Williams became two of its most notable figures. The former is credited with bringing Asian writing styles and myths to America, but he is greatly indebted to Ernest Fenollosa, a Harvard educated philologist who taught philosophy at the University of Tokyo in the last decades of the nineteenth century ("Fenollosa"). In addition to his intense passion for Japanese art, Fenollosa's conversion to Buddhism also attracted Snyder to his work. Snyder credits Fenollosa with giving him "further guidance into Asian art," which has greatly influenced his poetry (Mountains 153). It is through Fenollosa that the Imagist and Modernist movements share roots with the Transcendentalist era.

As a disciple of Emerson, Fenollosa extended his mentor's idea that nature had an intrinsic language (Seele). Subsequently, he arrived at the notion that "looking at 
Chinese characters you could see things themselves" (Seele). Five years after Fenollosa's death in 1908, his widow chose Pound as a suitable figure to continue her husband's work; she furnished the prominent architect of the Imagist and Modernist movements with the deceased's unpublished notes on Chinese poetry ("Fenollosa"). Her husband's work serves as the foundation for the Eastern ideas in Cathay (1915) and The Cantos, a project that spanned from 1915 to 1962 ("Ezra").

Amidst Fenollosa's collection passed on to Pound was an essay titled "The Chinese Written Character as a Medium for Poetry." Thus began Pound's fascination with the Chinese ideogram. In The Pound Era, Hugh Kenner describes Pound's relationship to Fenollosa that would later stir Snyder's interest in the bond between language and Eastern poetry: "An American mind, brought to ideographs by an art historian of Spanish descent who had been exposed to Transcendentalism" (44). Pound's ensuing interest in Chinese language culminated in his stature as a credible translator of Chinese poetry. His footing in the Imagist and Modernist movements and knowledge of the East formed an inimitable poetic style that attracted Snyder.

Pound's passion for the Chinese language led to his experimentation with presenting linguistic symbols in his poetry. This desire to represent the ideal unity between word and object provided the underpinning for the Modernist movement. Although Pound's translation skills are largely attributed to his interpretation of Fenollosa's work, it was the blending of his Modernist poetics with Eastern culture that ushered in a wave of Chinese literature and poetry. This development would greatly influence Snyder and future generations of poets. Pound's unique and diverse style of poetry transfigured the West's view of the East and fulfilled his pledge to take Western 
poetics and "make it new" (Kern, "Clearing" 160). However, in an interview with Ekbert Faas, Snyder states that his translation skills far exceeded both Pound and Fenollosa and that "the ideogrammic method was useful for us when we were young. Later, I went to study Chinese and realized how little Pound or even Fenollosa understood about how Chinese works" (132). Pound's Modernist style includes radically distorting Asian myths through the "collapsing of boundaries, categories, and concepts ... things flow into and from one another" (Qian 201). For instance, Pound associates "eunuchs, Taoists and Buddhists" when the original source "mentions only Buddhists" (197). His writing is heavily laden with inaccuracies of Chinese translation and misleading stereotypes, some unintentional and others purposeful (O'Conner). Although Snyder's poetry is infused with Buddhist and Native American myths, his works show a more careful attention toward presenting the two cultures positively.

Riprap reveals Snyder's budding passion for Japanese and Chinese poetry and represents an early interest in articulating Zen states of consciousness. The book reflects Zen's inward focus on meditation and contemplation through literalness and metonymy. This emerging style replaces the pervasive metaphorical imagery that underlies the adventures of Buddhist mythological figures like Maudgalyayana in Myths and Texts. Riprap still incorporates ancient myths, but in a way that resonates with the objectivity of Pound and William Carlos Williams. What Snyder borrows from Pound and Williams "is clear in Riprap's objectivity, terse rhythms and plain diction" (Kern, "Clearing" 161 ). Yao-fu Lin captures the germination of Snyder's emerging style that distinguishes itself from Imagism and Modernism. He writes, "Having the ability to read Chinese poetry in the original, an advantage neither Pound nor Williams enjoyed, Snyder was quite 
naturally influenced more profoundly by that poetry than either of the earlier masters" (366). Snyder's revolutionary style of poetry that capitalizes on his immersion in Eastern cultures led literary critic Thomas Parkinson to declare that the American-Buddhist poet "has created a new culture" (617).

In Riprap, the title poem introduces the term "riprap," which represents a stylistic and philosophical initiative that guides his early poetry and the majority of his later works. The literal definition of "riprap" is "a cobble of stone laid on steep slick rock to make a trail for horses in mountains" (Half title page). This metaphor for his poetry symbolizes a solid surface on which words can convey the concreteness of objects and ground the metaphysical properties of Zen. The book's overarching philosophy and style reveal nuances that differentiate Snyder's work from the Modernist imperative, as evidenced by his reconfiguration of Williams' famous line from "Paterson," "no ideas but in things" (Yip 50). Snyder's final two verses of "riprap" read "all change, in thoughts / as well as things" (Riprap 32). The modification reflects an absolute, all-encompassing reality where "all change" includes "thoughts," as well as objects in nature, or "things." In addition, Snyder's verse accommodates the Zen ideal of eliminating thoughts.

As a leader in the Modernist movement, Williams' vision of poetry aligns closely with Snyder's Buddhist aesthetics. For example, Williams' speaks "of the ability of words to take on a curious immediate quality quite apart from their meaning" (Yip 56) For Snyder the coalescing of Modernism with Zen is a perfect fit and an exemplary model of how the East and West can complement one another. The "non-verbal" realm may be considered an idealized aesthetic for Williams and Pound, but for Snyder, his creative authority as a Buddhist blurs the line between his poetic ambition and the Zen 
states of consciousness he portrays. What does seem clear is that Snyder fulfils Williams' poetic requisite for future poets: "Unless there is / a new mind there cannot be a new / line" (Yip 207).

\section{Conclusion}

Snyder's work falls in the category of postmodernism in part because of the heterogeneous perspectives he brings to poetry, such as those found in Buddhist and Native American cultures. Snyder's syncretism enables him to remake the poetic projects and Eastern influences of his predecessors into a viable poetics. Literary critic Robert Kern observes a common impulse between Fenollosa and Pound, which also applies to Snyder: "[T] he effort to see the world without language may itself be regarded as a thoroughly Western and American enterprise" ("Clearing" 180). Snyder's gravitation toward the "non-verbal" Void correlates with Pound's idea that "Chinese writing had an absolute and perfect relationship to its referent" (Yip 48). However, rather than rely solely on poetic ability and linguistic skills like translation, Snyder anchors his poetry in personal experiences based on idealized states of Zen, which remain unimaginable to most of the Western world. 


\section{CHAPTER II \\ THE “RAZOREDGE” BETWEEN EAST AND WEST}

\section{Introduction}

This chapter centers around Gary Snyder's poem "Sixth-Month Song in the Foothills," from his third book The Back Country. The poem represents the culmination of several techniques that reflect a keen understanding of Western poetics, as well as considerable insight into a Zen state of consciousness that closely resembles the concept of "Zen Mind." This mode of consciousness coheres with a "nondual" perception of reality. Dale Wright, author of Philosophical Meditations on Zen Buddhism, defines "Zen Mind" as an "un-mediated, direct awareness of things as they are" (165). In order to communicate this complex "awareness," Snyder combines his "riprap" style with ordinary scenes from nature to develop the impression of the subject interfused with the nonhuman realm. The result is an appearance of neutrality with the life forms around the subject, which fits the Buddhist principle of "interdependence," or pratītya samutpāda. Wright defines the latter Sanskrit term as: "Things are 'open' insofar as other things enter into them, insofar as their boundaries are not fixed or static but permeable and changing" (53). The poem exemplifies Snyder's unique ability to make the particular in nature shine, while fusing it with an awareness of the infinite. 
The strategies that produce the theme of "interdependence" and capture the aesthetics of Eastern poetry in "Sixth-Month Song" include suppressing personal pronouns, omitting articles, and the prominent use of participles. The conglomeration of these tactics shows a subject working in harmony with the natural world and forms what I refer to as the "aesthetic of neutrality." This aspect of the poem involves the Buddhist concept of "nonduality." The latter indicates "Zen Mind's" unique perception as "a collectedness of mind or meditative absorption in which all dualistic distinctions like I/you, subject/object, and true/false are eliminated" (Diener, et al 261). Snyder fluidly intermixes opposing images and ideas in the poem to blur the boundaries of "dualistic distinctions." This technique reveals the "dualistic" subject/object construction (within the subject's identity) and allows a "nondual" understanding to take place in the reader.

After a brief contextualization of The Back Country, I closely examine "Sixth Month Song" from a Buddhist perspective that focuses on Snyder's use of syntactical devices and the influence of haiku and the koan. In Charles Altieri's seminal work, Enlarging the Temple: New Directions in American Poetry During the 1960s, he examines Snyder's poem by relying on the "poetics of presence" model. This Western poetic style explores the mind's intense experience of "pure presence" through radical immanence (9). The main argument of this chapter is that Altieri's application of the "poetics of presence" model marginalizes the Zen and Buddhist dimensions in "SixthMonth Song." In particular, I will show the importance of the Eastern forms of haiku and the Zen koan, which reveal a new relationship between the poem and "pure presence." The thrust of this claim revolves around my reading of the poem's only personal pronoun as an overtly possessive thought that disrupts the "Zen Mind" and reveals the emergence 
of a "dualistic" mind. This interpretation confirms a distinct difference between "Zen Mind" and Altieri's conception of the poem through the "poetics of presence" model. One purpose of this chapter and indeed the entire thesis is to magnify the success or failure of Snyder's poetry to measure up to his poetic ideal of providing "a riprap on the slick rock of metaphysics" (43).

"Sixth-Month Song" from The Back Country epitomizes the style of Snyder's first book Riprap, where the guiding notion rests on the idea that poetry can infuse words with a solidity like rocks. Both books contrast greatly with the charged atmosphere of his second published book, Myths and Texts, which draws upon a diverse range of mythological figures from Buddhism and Native American culture. The Back Country revolves around Snyder's travels, with the section "Far East" representing his years in Japan, and "Kali" drawing on his visit to India in 1962 (Paul 228). The images of travel and sense of place serve as the controlling metaphors. Charles Molesworth observes that the back country "has three associations, the wilderness, the backward countries, and the back country of the mind with its levels of being in the unconscious" (61). Snyder's coverage of these topics includes subjects ranging from wretched poverty to sexual passion. The book as a whole focuses on love, friendship, and the accumulated wisdom of Snyder's life as a disciplined Buddhist. Literary critic Sherman Paul writes, "Now experience is compounded by remembering and deepening of life" (225). Although some of Snyder's poems contain allusions to obscure Buddhist culture and Zen practice, "Sixth-Month Song" possesses a rhythm of "tough, simple, short words" that embodies Chinese poetry (Murphy 45). However, Snyder also acknowledges a "surface simplicity set with unsettling depths" in his works (Riprap 67). The next section presents a close 
reading of the poem from a Buddhist perspective and also incorporates some of Altieri's observations about the poem.

\section{A Buddhist Perspective on "Sixth-Month Song in the Foothills"}

The first line introduces an objective scene where the impersonal description of a "cold shed" complements the "sharpening" of saws. Each of the three stanzas begins in or near the shed and opens up to the infinite world beyond its walls:

In the cold shed sharpening saws. a swallow's nest hangs by the door setting rakers in sunlight falling from meadow through doorframe swallows flit under the eaves.

Grinding the falling axe sharp for the summer a swallow shooting out over. over the river, snow on low hills sharpening wedges for splitting.

Beyond the low hills, white mountains and now snow is melting. sharpening tools; pack horses grazing new grass bright axes-and swallows fly in to my shed. (9)

The first stanza combines generic nature images like "a swallow's nest hangs" with signs of human intervention, for instance, the "shed," "door," "doorframe," and "eaves." As the poem progresses, rather than disturb the wildlife, the shed provides shelter for Snyder and a home for the swallows. Snyder's work of sharpening his tools runs parallel with the swallows flying to and from their nest and is heightened by the lack of any subjective intrusion. Then, in the final line, the objective view of the actor in harmony with his surroundings is ended when the ego appears in the form of a personal pronoun. 
The second stanza begins with a grinding axe, and so as in the first, the human effort sinuously fits in with the other activity around the shed. With the exception of line six, his actions take place through the use of participles and without articles before the objects that Snyder controls. In Altieri’s chapter “Process as Plenitude: The Poetry of Gary Snyder and Robert Duncan," from Enlarging the Temple, he notes that Snyder's utilization of participles is reminiscent of Fenollosa's notion that "what one tends to see as entities are in fact states of action; verbs approach substance and nouns become active" (136). Altieri describes this technique by stating that the "almost dangling participles ... blend actor and action, man and world" (134). Though his remark is positive, the use of "blend" conflicts with the Zen notion that the subject/object binary dissolves. The potent use of participles in the poem emphasizes ongoing action and helps create the appearance of an egoless subject. This "pure presence" exhibited by the Snyderian subject resembles a remark by John Irwin about Walt Whitman's poetry: "In the ideal transparency of embodiment, the singer becomes the song" (40). While Irwin's observation appears to fit the Zen concept of 'living in the present moment,' which the poem's subject embodies, a Buddhist perspective reveals substantial differences between the two perceptions.

The subjectivity of the poem's actor has dissolved or borders on being eliminated in "Sixth-Month Song." Altieri acknowledges Snyder's "awakening mind" and references his term "razoredge" in order to delineate the boundary "where man's attention meets the world" (135). The complete journal entry that Altieri draws upon comes from Earth, where it alludes to a famous Zen koan, in which a teacher's utterance of "MU" (no or not) triggers a student's enlightenment (41). Altieri's explanation of the "razoredge" in the poem suggests a cursory analysis of the Zen content and signals an 
inadequate inquiry into Snyder's internalization of Eastern thought. Altieri also offers an anthropomorphic observation that closely resembles "Zen Mind": "The ideal of 'presence' then necessarily involves a harmony with natural rhythms-in fact to a dualist or humanist it approximates the non-reflective existence of animals" (187). However, his use of "approximates" to compare him with an animal mind indicates a resistance to any ultimate status as "pure presence." Anthropomorphism and the Cartesian divide between subject and object provide a constructive entry point for investigating the "poetics of presence" in the West and "pure presence" in Zen.

The rationale for Altieri's denial of "pure presence" is explored throughout Enlarging the Temple. For example, he links Snyder with American poet Denise Levertov because of their "reliance on strategies of perception or imaginative stances" that leave "the self helpless or pathetic in relation to social forces" (237). Altieri refers to these visionary moments as "terribly evanescent" and concludes that the intense experiences cannot translate into a meaningful source of ethics and values available to the rational mind (237). A great deal of the skepticism that revolves around the possibility of "pure presence" in Snyder's poetry arises from the idea of a "nondualistic" consciousness. In Waltraud Mitgutsch's essay, “Gary Snyder's Poetry: A Fusion of East and West," he asserts that "[1]etting go of the self is a precarious experiment for Western man; it implies the danger of losing his consciousness and thus his self" (435). While this observation is valid, Buddhism views ordinary language as illusory and the elimination of the subject/object binary as an opportunistic experience that liberates one from the "dualistic" construction of the self. 
Mahayana Buddhism describes this condition through a variety of terms including "Tathata" or the "suchness" of reality. To know the "suchness" of "reality" is to see things "as they are in themselves, to understand them in their state of self-nature" (Crittenden 52). The term also is expressed as going "back to a state of mind before the division of the knowing and the known takes place" (52). When the self experiences the "suchness" of phenomena, reality is said to take the form of a "non-conceptualized" perception. This experience of reality is unimaginable to most of Western culture and can create considerable anxiety as evidenced by Mitgutsch and Altieri's remarks.

While communicating the experience of core Buddhist concepts will not resolve the poem's intricate association with an ideal "presence," a study of the relationship is lacking without an exploration of the otherness of Zen. In order to communicate "Zen Mind" and Buddhist discourse through Western poetics, Snyder relies heavily on the compression of Chinese and Japanese poetry. In Diffusion of Distances, Wai-lim Yip reinforces the importance of grammar to understanding Eastern modes of thought when he states, "syntax is in many ways inseparable from perception" (2). In a subtle way, Snyder manipulates the syntax to subordinate the actor to the landscape. Omitting articles and using participles to convey his actions related to chopping wood enhances the objective tone, as well as the theme of "interdependence" and the aesthetic of neutrality. Common nouns on the other hand, like "swallows" and "eaves," regularly receive articles. Snyder also expresses the harmony between inner peace and external forms by avoiding personal pronouns (until the poem's penultimate word). Altieri approaches Snyder's poetry with considerable attention focused on the nuances of Western grammar 
and addresses Eastern aesthetics, but ultimately, the Western "poetics of presence" model is privileged over Buddhist aesthetics.

As the scene expands to the mountains in the third stanza, a favorite image of Buddhist "interdependence," Snyder refrains from transforming the landscape into a sacred symbol of the infinite. The nondescript "sunlight" "falling from meadow" in the first stanza, coheres with the unexceptional descriptions of different forms of water in the second stanza: "over the river, snow on low hills" (9). The rare use of prepositions that precede "river" and "snow" diffuses any action or flux in the scene. The third stanza continues the generic, objective, panoramic view around the shed. Literary critic Jody Norton describes this aesthetic that materializes from the austere imagery when she writes: "Gary Snyder's poems sheer away from abstractions, delineating the material world boldly in series of concrete images" (167). The strategy of suppressing descriptors fits the modernist poetic style and complements the initiative of Riprap, wherein Snyder seeks to render the concreteness of objects - words are like rocks. The "rip-rapping" style also benefits from two forms of syntactical ellipsis, omitting articles in relation to Snyder's actions and suppressing personal pronouns. These techniques help create the aesthetic of a neutral subjectivity and enhance the Buddhist theme of "interdependence."

The absence of ego-centeredness or a reflective consciousness, and the analogous actions between the subject and the animals in "Sixth-Month Song," suggest a realization of the Buddhist concept of "no self." This state is integral to the West's understanding of "Zen Mind," but often misinterpreted as "absence" in the context of the "aesthetics of presence." Dale Wright defines "no self" as a realization that occurs when the ordinary "self" dissolves into "an awareness - said to be inexpressible with words - in which the 
distinction between subject and object drops away" (18). The term which is a central feature of "Zen Mind" represents an awareness that troubles Western critics and poets. Mitgutsch, referring to Snyder's Zen ideal of 'letting go of the self,' asserts that "it is unlikely that the mere adaptation of a philosophical system would be able to extinguish a basic human fear reaching down to the roots of consciousness" (435). Similarly, literary critic Thomas Parkinson denies the transcendent quality of Snyder's Zen state of consciousness, noting that "Everything is too simple, too easy, too glib, a boy's book in verse, Huck Finn on the Skagit, Innocents in Japan" (631). Snyder's suppressing of personal pronouns and omitting of articles symbolize "no self" and "pure presence," but the West's anxiety over "losing the self" make the subject's condition unimaginable. In addition to exploring this impasse, my analysis of "Sixth-Month Song" exposes a broader issue that is beyond the scope of this thesis. The problem, evident in Parkinson's statement above, should nevertheless be acknowledged by the reader of Snyder's poetry. The dilemma relates to whether Western literary models are adequate to gauge the authenticity of Snyder's depictions of Zen states of consciousness when the critic lacks the insight into its disciplined meditation practice.

Alongside Buddhist concepts like "no self" and "interdependence" is the notion of a "nondualistic" experience of reality. The latter term refers to a "non-conceptualized" perception that reveals the "suchness" of things, as opposed to ordinary "dualistic" awareness. Christopher Ives, author of Zen Awakening and Society, describes "dualism" as "part of being human" where one "becomes cut off from the world ... lost in concept about and reactions to reality and becomes attached to objects or situations that seem to promote security yet inevitably change" (17-18). Altieri's conclusion related to the 
'blending' of the subject/object dichotomy within the "self" can be characterized as approaching the boundary between "dualism" and "nondualism," or Snyder's "razoredge." However, significant differences exist between the Eastern and Western models that explain the dichotomous terms. For example, Altieri observes that "balanced spatial elements" such as the shed and the surrounding natural world "enter a complex relationship evoking the balance of inner and outer life, smallness and infinity, created by a full awareness of the force of spring" (135). This description fits the scene, but his observation ends with the blurring of the small and infinite, and as a result, diminishes the evolving aesthetic of Buddhist "nondualism."

In the second stanza of "Sixth-Month Song," Snyder disrupts the reader's preconceived notions about the seasons in order to communicate the "nondual" perception of "Zen Mind." The preparedness for summer in line seven reveals the season to be spring. The stanza shows nature at a standstill and heightens the anticipation of summer. The words "Summer" and "snow" in the second stanza create a dynamic contrast that draws attention to the "cold shed" in the opening line (1). The participle "falling" functions as a polyptoton for "the fall" season and completes the imagery of the four seasons. The swallows nesting inside the shed now are connected with a swallow flying "over the river" (8). Snyder's blurring of the boundary between the small and the infinite and his disruption of preconceived notions about the seasons combine to distinguish this effort of portraying a Zen state of consciousness from his earlier ones. 


\section{Differentiating “Zen Mind" from a "Dualistic" Mind}

The third and final stanza breaks up the continuity of ongoing activities such as "sharpening tools" and "pack horses grazing." The motionless "bright axes" stand out in relation to the subject's previous actions involving tools - "Grinding" and "sharpening" for instance. The final line is suddenly transformed into the "present moment" with the second present tense verb of the poem, "fly" (the other, "flit," appears in line five). Up to this point Snyder positioned himself as a thoroughly objective speaker, but with the possessive pronoun "my," a reflective consciousness enters the scene:

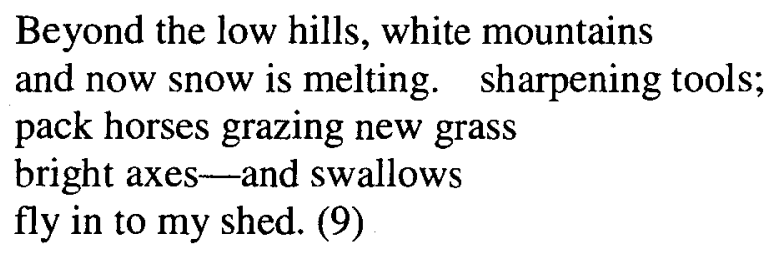

The panoramic view of the happenings around the shed changes from a pattern of continued action to a fleeting moment. The image of the subject in harmony with his surroundings is disrupted as the ego appears in the words "my shed" and signals a verbal reality where earlier there was none.

"Sixth-Month Song" works hermeneutically by allowing the reader to experience Buddhist insights such as "interdependence," then forcing him or her to reconcile the "nondualistic" "Zen Mind" with the possessive "dualistic" mind. My reading of the poem's only personal pronoun as a tactic to differentiate between an ego-centered mind and "Zen Mind" illuminates the unified consciousness of the subject. Zen Buddhist philosopher Alan Watts, to whom Snyder dedicated The Old Ways, writes that in Zen, "the desire to possess is abandoned because there is nothing that can possess and nothing that can be possessed" (112). The two clashing mindsets within the same subject 
intensify the aesthetic of neutrality and "nonduality" that embody the "Zen Mind." The immediate awareness from the drastic shift in consciousness accentuates the positive qualities of the Zen state of consciousness. Furthermore, the forced reconciliation of the two idiosyncratic perspectives parallels the paradoxical strategies of Zen teachings, which aim to evoke a less mediated more direct perception of reality.

The poem's ending depicts the Buddhist idea of human attachment to the material world and conflicts with the notion of "no self." Charles Altieri concludes that "The whole poem serves to set off Snyder's subjectivity, to preserve it while showing that it achieves its fullness only when in total harmony with the processes of the world in which it dwells" (136). I argue that a Buddhist perspective that includes a close examination of haiku and the Zen koan provides a more accurate understanding of Snyder's Buddhist ideas in "Sixth-Month Song." While haiku forces a more immediate interpretation, koans function over time, often posed as a question that invades the consciousness. However, both forms are renowned for their ability to evoke a spontaneous apprehension of reality in the mind of the prepared Zen practitioner. The sharp contrast of the "Zen Mind" with the possessive ego-centered mind, represented by the personal pronoun, parallels the haiku and koan's techniques for provoking an immediate intuition or enlightenment.

The final line fits a strategy of disrupting the rational "dualistic" mind to force a nonrational understanding of a truth, also known in Zen as the "rhetoric of disruption." This Zen term encompasses the koan and fits with the reading of the personal pronoun as a device to emphasize the two clashing states of consciousness in "Sixth-Month Song." Dale Wright states that the "rhetoric of disruption" is designed to disorient, cut "through ordinary experience and thus also ordinary linguistic forms" (96). The method is used in 
live interactions between an experienced Zen teacher and student in a monastic setting, where words, noises, and silence are delivered in highly unorthodox ways intended to trigger a spontaneous intuition (96). Buddhist scholar G. Victor Sōgen Hori defines the Zen koan as follows: "The koan gives the appearance of having rational or cognitive content described in a factual or a metaphorical way deliberately to deceive us in order to perform its true task: to make us 'stop intellectualizing"' (285). Snyder's absorption of this Zen form into his idiosyncratic Buddhist poetics appears in the ego-centered possessiveness of "my shed." The personal pronoun serves to emphatically delineate "Zen mind" from "dualistic" consciousness, creating the possibility for an immediate insight into the "razoredge." Buddhist commentator A.C. Graham describes a Zen koan strategy that parallels the end of "Sixth-Month Song." He writes, "By moving the point of reference of the maker of the distinction (e.g., from the top of a hill to the bottom of the hill) the opposites are identified" (Hori 289). Instead of passively imagining Buddhist concepts like "no self" and "interdependence," the radical shift in consciousness abruptly ends the depiction of "Zen Mind," and creates the possibility of spontaneous insight into the "nondualistic" Zen state of consciousness.

Like fellow "Beat Generation" authors Alan Watts and Jack Kerouac, also engrossed with Buddhism, Snyder altered the haiku form to adapt it to the English language. His suppressions of articles and personal pronouns accentuate his deliberately choppy tone and echo the compression of haiku. The poetic form was assimilated into Zen practice for its capacity to communicate concrete experiences and deep intuitions, or what poet and Buddhist commentator Robert Haas describes as a "moment seized on and purely rendered" (xiv). Prior to the final line of "Sixth Month Song," the "rip-rapping" 
rhythm of simple rocklike words reflects Snyder's view of Zen as inwardly meditative and contemplative. Snyder writes this about haiku: "The words stop but the meaning goes on" (Real Work 22). The most important aspect of the haiku is the juxtaposition of contrasting images set apart by a break or "cutting word" (Trumbull). Acting like a caesura, this break separates one of the three lines as a fragment with the intention of creating immediate perception that is without judgment and conscious reasoning. Snyder offers a more intense interpretation of the experience, saying it feels "like sharp blows on the mind" (Bloom 358). Consequently, haiku has been said to bring about Buddhist enlightenment in the proper setting and when received by the prepared "Zen Mind." When oriented within the Buddhist aesthetics of "Sixth-Month Song," the subjectivity in the last two words - "my shed" - is conspicuous and closely resembles the "cutting word" in haiku.

The subjective rational mind at the end of the poem creates distance from the earlier "total presence" of the actor. The last line, with its five monosyllabic words, switches from the predominantly choppy tone and haiku-like rhythm to an orderly syntax that mirrors the Western rational mind. The following observation of haiku by Norton matches the style leading up to the final line in "Sixth-Month Song." She writes that images "are brought together without any overt narrative or figural connection" (176). Poets that are adept at the art of haiku recognize the inherent limitations of conventional language and logical linguistic structures to represent Zen states of consciousness. The last line abandons the haiku-like style and instead adheres to the normal English sentence order (subject-verb-object/complement). The verb in the final verse also changes to the 
present tense. Ironically, the last two verses form the most coherent proposition of the poem, yet signal a possessive nature linked with an ego-centered consciousness.

The syntactical strategy at the end of "Sixth-Month Song" embraces paradox, which is the basis for the "rhetoric of disruption." Paradox and rhetorical tactics like irony are also found in Western literary models. In Enlarging the Temple, Altieri remarks on New Criticism's unease with attempting to capture the "ideal of rendering experience" through radical rhetorical modes like "irony" (23). Referring to the literary movement, he writes, "For them only a complex paradoxical rhetorical structure could make the poem sufficiently nondiscursive to render experiences (usually tragic ones) not reducible to modes of analysis dependent on traditional logic" (23). Altieri notes the literary movement's abandonment of the "nondiscursive" model and his tone in the above statement implies he too has doubts about the idealistic goal of the New Critics. He goes on to explain his own strategies for a "nondiscursive" methodology that investigates "the poem's relationship to nonlinguistic experience" (23). However, as a Buddhist perspective shows, the New Critics' focus on a "complex paradoxical rhetorical structure" that is abandoned proves to be one of the most effective literary tools for unfolding Snyder's creative strategy involving the personal pronoun (23). Paradox and contradiction are central to understanding Snyder's idiosyncratic Buddhist poetics and potentially improving the reader's perception of the "razoredge."

\section{The "Poetics of Presence"}

The "nondualistic" property of "Zen Mind" embodies "pure presence" and therefore represents the height of the "poetics of presence." In addition to Snyder, the 
genre includes other notable innovators such as W. S. Merwin, Robert Creeley, Robert Duncan, and Denise Levertov. Beneath the style and form of this diverse poetry lies Western culture's preoccupation with an individual's desire to experience "pure presence." German philosopher Martin Heidegger termed this ideal state "being-aspresence."

Charles Altieri thoroughly investigates the "poetics of presence" in his book Enlarging the Temple. He observes that Creeley, "like most important poets, is trying to resolve the dualisms of man and nature, subject and object, and embody their harmonious interrelationships in his poems" (188). The popularity of Buddhism has grown significantly since the 1960 's, yet the substitution of critical Western philosophical terms like "dualisms" for the Buddhist meaning of the word still remains problematic. Similarly, supplanting the Western concept of "harmonious interrelationships" proves inadequate for expressing Buddhist "interdependence." Although Altieri's theories reveal tremendous insights and similarities between the "poetics of presence" and Snyder's poetry, the common ground wavers when "pure presence" as a symbol of the East confronts the skepticism of postmodern thought in Western culture. When Altieri parallels Buddhist thought with Western thought, he confirms preexisting positions without rethinking them from an Eastern perspective.

Creeley and Merwin incorporated Buddhist thought into their poetry, with the latter integrating extensive translation experience and intensive study of Japanese poetry and Zen (Aitken 13). Both poets and Snyder differ drastically from each other in regard to addressing existential matters or Zen states of consciousness in their poetry. Altieri describes Creeley as "intensely impersonal" and Merwin as exploring "radically abstract 
impersonal and surreal states of mind" (19). However, Creeley and Merwin agree on one fundamental point that separates them from Snyder. According to Altieri, they "both share a sense that at the very moment of intense awareness of presence there is produced a terrifying self-consciousness" (19). Snyder's work occasionally explores the dark forces of life through nature and the unconscious, but unlike the poetry of his two contemporaries, the moment when "pure presence" arises rarely involves the mind's desperate struggle for certitude amidst prevailing doubt and confusion. Instead, his portrayal of Zen states of consciousness infers that intense meditation and contemplation have laid the foundation for the "direct intuition" that he aims to convey to the reader. The skepticism toward a profound experience relating to "pure presence" originates in large part because of the West's inability to verify or totally disqualify Zen's disciplined approach to consciousness. This meditative self-disciplined practice purportedly liberates one from the mind's endless and chaotic mental representations. Snyder captures this idea in his essay "Buddhism and the Coming Revolution" when he writes, "Meditation is going into the mind to see this for yourself—over and over again, until it becomes the mind you live in" (Earth 92). Like Altieri, literary critic Thomas Parkinson sometimes finds Snyder's poetry too far removed from ordinary consciousness and confronts the "mystique" of his "highly limited Zen Buddhism sect" (631). He critiques Snyder's tone by stating, "Like most writers with a coherent world view, he sometimes refuses to let his material be intractable, there is no sense of contention between subject and object, no dramatic struggle toward a new form" (631). Roy Okada, in his dissertation "Zen and the Poetry of Gary Snyder," echoes the spirit of Parkinson's argument. He notes "an almost casual air" regarding the attainment of Buddhist 
enlightenment in a journal entry from Earth: "Almost had it last night: no identity" (15). The idea that Zen states of consciousness should involve a struggle at the moment of transformation reveals preconceived notions built into Western literary models and thought.

In the introduction to Enlarging the Temple, Altieri discusses his methodology for applying the "poetics of presence" model. His process includes insisting "on the nondiscursive immediacy of one's encounter with the poem and of the poem's relationship to nonlinguistic experience" (23). While this tactic is worthwhile and proposes an uncritical attitude toward exploring Eastern modes of consciousness, Altieri's approach also reveals a contradictory view of Zen as "other." The inconsistency surfaces when he praises Snyder for communicating "a non-Western frame of mind without references to occult philosophy or a series of abstractions (135)." He approaches Snyder's poetry with considerable attention focused on the nuances of grammar, but does not penetrate deeply enough into the aesthetics of Eastern poetry and Buddhist philosophy and discourse. Ultimately, the Western "poetics of presence" model is privileged over the "pure presence" that accompanies "Zen mind." Altieri's view of certain areas of Zen practice and Buddhist culture as "occult philosophy and a series of abstractions" results in a reading of "Sixth-Month Song" that overlooks the significance of haiku and the koan (135). He focuses on Snyder's ability to express Zen philosophy through an American idiom. However, Snyder's aim also includes communicating the depths of Buddhist thought to Western culture - bringing the West to the East. 


\section{Conclusion}

Literary theorist Roland Barthes is an exception to the argument that Western critical methods often fail to fully engage the aesthetics and poetic forms of the East. In Empire of Signs, he confronts haiku's power to halt language and presents a viewpoint that bolsters the possibility of "pure presence" in "Sixth-Month Song." Barthes states that "haiku is merely the literary branch" of Zen and is not based on a "mystical silence," but rather "an enormous praxis destined to halt language ... to stupefy, to dry up the soul's incoercible babble; and perhaps what Zen calls satori" (74). He expands on the idea of satori or Buddhist enlightenment by saying that it is "no more than a panic suspension of language, the blank which erases in us the reign of Codes" (75). However, Barthes' intention of corroborating enlightenment through Western thought is highly problematic given his lack of authentic Zen experience. His conclusions about the relationship between haiku and enlightenment introduce the problem of how much insight a Westerner has in describing a Zen state of consciousness. Likewise, this same question of authenticity must also be directed at Snyder.

Snyder's Rinzai Zen studies in Japan amounted to less than two years when his first book Riprap (1959) was published, and yet he provides in depth portrayals of śunyată, or Buddhist ultimacy. His knowledge of enlightenment and the Void is the source of considerable speculation from literary critics and contemporary philosophers, some of whom claim to have firsthand knowledge of Zen. His affinity for exploring the complex and contradictory relationship between silence and language in his poetry complicates any effort to determine Snyder's degree of insight into "Zen Mind." Snyder's level of experience with respect to Zen states of consciousness is knotted in his 
poetry and public persona. Both subjects receive careful attention in the remaining chapters of this thesis since they are integral to gauging the success to which his idiosyncratic Buddhist poetics strengthens the reader's perception of the "razoredge." 


\section{CHAPTER III}

\section{MENDING THE FRACTURED IDENTITY IN "PIUTE CREEK"}

\section{Introduction}

This chapter examines "Piute Creek," which features one of Gary Snyder's earliest conceptions of śünyatä. This Sanskrit term is known in the West as the Void or "emptiness," and also represents Buddhist ultimacy. The poem appears in Riprap, his first published book, and has garnered a great deal of attention from literary critics since it represents the height of his poetic ambition - conveying the "non-verbal" realization of the Void. In "Piute Creek," Snyder draws on the key Buddhist concepts of "no self," “co-dependent arising," and "nonduality," which are indispensable to a complete rendering of śünyatā. In Zen Awakening and Society, Christopher Ives defines the Void as "the lack of any independent essence or self in things and the interrelational dynamism that constitutes things" (2). This explanation of Buddhist ultimacy as simultaneous absence and plentitude proves useful as Snyder's portrayal of the Zen state of consciousness unfolds.

In Snyder's prose book The Old Ways (1977), the Native American mythical Coyote is a trickster figure who exhibits mystical and creative energy, meddles with humanity, sometimes brings death, and has a prominent role in several creation myths. The capricious animal surfaces toward the end of "Piute Creek" and reacts in an 
uncharacteristically docile manner toward the poem's subject. This relationship serves as the focal point for my approach to the poem from a Buddhist perspective.

This chapter begins with a close reading of the two-stanza poem, which clearly distinguishes between an unenlightened mind and an enlightened one. My analysis forms the groundwork for a reading of the last verse as an allusion to twelfth century Zen master Dōgen's description of enlightenment. Next, I take issue with literary critic Tim Dean's anthropomorphic reading of the Coyote from his book Gary Snyder and the American Unconscious. His conclusion rests upon French philosopher Jacques Lacan's theory of the "mirror stage," where a psychological split between "self" and "Other" exists within one's identity (171). With a purely subjective perception established, Dean applies the Kantian sublime and contemporary philosopher Neil Hertz' modifications to Kant's ideas, to "Piute Creek." The result is a misguided reduction of the poem to a Transcendentalist text. By analyzing the relationship between the Coyote and the subject, I will demonstrate that a dominant aesthetic of "nonduality" supersedes Dean's reading. My phrase "aesthetic of "nonduality" refers to the growing perception of a "unified, nondualistic experience [that] is prior to and envelopes the normal dualistic view that the 'self' has an experience of something" (Ives 21). The Coyote's presence then complements rather than disrupts the Void. Although Western literary models are vital to enriching and illuminating Snyder's poetry, this chapter of the thesis, like the previous one, seeks to show that a more accurate picture forms when the critical methods of the East and West converge. 


\section{A Buddhist Perspective on "Piute Creek"}

"Piute Creek's" portrayal of the Void resonates with a non-transcendental tone that reflects Zen's emphasis on inward meditation and contemplation. In his book Gary Snyder's Vision, Charles Molesworth alludes to this quality when he links Snyder's poem to an aesthetic associated with the Imagists. He writes, "the imagists sought to reenergize the prearranged world of routinized, mundane experience ... displaying a poetry of flat surfaces devoid of any transcendent dimension" (13). Even when the ground "wavers," Snyder represents the landscape through nondescript images (13). The poem also displays Snyder's expertise in the concise poetic form of haiku. However, since his intended audience lacks direct insight into Eastern modes of thought, he faces the difficult task of introducing the Western reader to the pinnacle of Buddhist philosophy and bringing the reader to the "razoredge." Through his idiosyncratic Buddhist poetics, Snyder successfully conveys many of the important concepts that form the aesthetic of "nonduality," which is critical to portraying the multidimensional Void.

Rocks provide the dominant symbol in "Piute Creek." Their appearance as both static objects and trembling ground symbolizes a changing consciousness and reveals the illusory quality of perceived boundaries in nature. In line eight of the first stanza, the unexceptional nature imagery is interrupted by the subject's consciousness, "A huge moon on it all, is too much." Besieged by the subliminity that emanates from the landscape, "The mind wanders" (9). The opening lines gradually build to a momentary awe and the subject becomes temporarily overwhelmed by the landscape:

One granite ridge

A tree, would be enough

Or even a rock, a small creek,

A bark shred in a pool. 
Hill beyond hill, folded and twisted

Tough trees crammed

In thin stone fractures

A huge moon on it all, is too much.

The mind wanders. A million

Summers, night air still and the rocks

Warm. Sky over endless mountains

All the junk that goes with being human

Drops away, hard rock wavers

Even the heavy present seems to fail

This bubble of a heart.

Words and books

Like a small creek off a high ledge

Gone in the dry air. (1-18)

The spatial ellipsis and dissolving of perceptual boundaries between the sky and mountains in line eleven signal a shift in perception. The mind's awareness intensifies as "All the junk that goes with being human / Drops away, hard rock wavers" (12-13).

Before the gradually rising tension can turn rapturous, a Zen-like affection shifts the focus to a heightened inner awareness: "Even the heavy present fails" (14). Despite the changing consciousness, the imagery remains subdued and adheres to the design of Riprap, where rocklike words convey the concreteness of objects. The result is a nontranscendental tone that distances itself from the poetic traditions that fixate on nature for spiritual fulfillment, such as Transcendentalism.

In the final three lines of the first stanza, a metaphorical flight of mind transpires. The ordinary consciousness of the subject fades "Like a small creek off a high ledge" (17). This simile serves to demarcate the unenlightened mind from the ensuing Zen state of consciousness, and also begins a pattern of suppressing metaphor. The metaphor of going over a ledge into empty space symbolizes an encounter with the Void, while the space between the stanzas signifies "emptiness." In the first line of the second and final 
stanza, the article " $\mathrm{A}$ " before "clear, attentive mind" changes the tone from one of personal narrative to absolute objectivity (19):

A clear, attentive mind

Has no meaning but that

Which sees is truly seen

No one loves rock, yet we are here

Night chills. A flick

In the moonlight

Slips into Juniper shadow:

Back there unseen

Cold proud eyes

Of Cougar or Coyote

Watch me rise and go. (19-29)

Lines nineteen through twenty-one construe an enlightened mind which "[h]as no meaning but that / Which sees is truly seen" (8). From a Buddhist perspective, the first three lines of the second stanza authenticate the realization of the Void. However, the Zen discourse is at odds with the ephemeral nature images and the poem's overall aesthetic of "nonduality" since a rational explication of the Void amounts to naming what Snyder says can only be "hinted at" (Real Work 21). Charles Altieri correctly observes that "[s]o much pointing asserts the referential power of language and denies the selfreflexive implications that accompany more metaphoric styles" (134-135). One possibility for the didactic tone is that Snyder's idiosyncratic Buddhist poetics must stray from the threshold of a "non-verbal" experience, where poetry has less "real magic," in order to educate an audience that lacks direct insight into Zen practice and studies (Snyder, Real Work 21).

In this "nondualistic" realm of the Void, where experience is said to be "nonverbal" and ineffable, the term "no self" once again provides a suitable means for articulating the Zen state of consciousness. In Philosophical Meditations on Zen 
Buddhism, Wright defines "no self" as a realization that occurs when the ordinary "self" dissolves into "an awareness - said to be inexpressible with words - in which the distinction between subject and object drops away" (18). Snyder's remark in the Afterward of Riprap insinuates that he has had direct contact with this profound realization. He writes that "Riprap celebrates ... my first glimpse of the image of the whole universe as interconnected, interpenetrating, mutually reflecting, and mutually embracing" (65-66). This intricately arrived at consciousness embodies "pure presence."

The first three lines of stanza two feature a discursive description of the Void. The succeeding line returns to the theme of the rocks. In this particular context, "rock" forms the crux of the poem's most enigmatic verse: "No one loves rock, yet we are here" (22). A quizzical, distant voice delivers the nonrational line. It points out the obvious but thought-provoking idea, that humans don't project their attributes onto rocks. The koan-like quality of the line is supported by Wright's historical observation regarding Zen. He states, "In many classical Zen narratives, disruption and disorientation are hastened through the use of negative language, which disrupts conventional practices and beliefs" (98). The striking contrast between rock and love intensifies the physical and psychological implications of "here" and gives the line a metaphysical tone.

The next three lines rely on nature imagery to convey the impermanent quality of the Void. Snyder writes, "Night chills. A flick / In the moonlight / Slips into Juniper shadow" (23-25). These unique glimpses of nature are heightened by the contrast between moonlight and shadow. The two opposing images are fluidly mixed and the blurring of their boundaries accentuates the aesthetic of "nonduality." Despite the uneven contrast between the didactic approach and vivid nature imagery in the second 
stanza, the poem effectively sets off the Zen state of consciousness. Finally, the presence of the Native American Coyote figure, set against some of nature's rarest sights, merges with the Buddhist themes and images to enhance the dynamism of the Void.

\section{Tim Dean's Reading of the Coyote}

In Tim Dean's reading of the Coyote, anthropomorphism leads to a fracturing of the subject's identity that consequently invalidates Snyder's portrayal of the Void. By examining the relationship between the Coyote and the subject from a Buddhist perspective, I will attempt to reveal an aesthetic of "nonduality" that supersedes Dean's reading. The Coyote enters the scene in the last four lines and adds a mythical dimension to the poem. Enveloped in ephemeral imagery, the Coyote's presence heightens the sense of "interdependence." As in the first stanza where the mind takes flight, a ledge is again used to symbolize a spiritual ascension. Dean recognizes the subject's "ascetic transformation" when he states, "linguistic representation fails the experience and the poem temporarily ceases" (169). However, he does not address any Buddhist dimensions that permeate the visionary moment.

The "proud eyes" of the unpredictable, power-wielding figure are a benevolent sign that corresponds to the subject's heightening awareness (27). Dean's reading of the poem's shift in focus from the subject to the Coyote is as follows: "Although the trace of anthropomorphism at the poem's end - in which the beast is attributed some hauteur (without being observed) and reified by the capital letter - weakens the effect, this is a quite brilliant and complex poem" (167). Once the subject becomes the object of the Coyote's gaze, Dean asserts that the former's identity is fractured by an already existing 
"misrecognition of the self in the 'Other' - which forms the basis for all subsequent identifications" (171). The basis for this disjointed identity that forms during infancy and childhood, and which manifests on the unconscious level, depends on psychoanalyst Jacques Lacan's model. His theories involve a strong association between language and the unconscious, two central concerns in Snyder's poetry, prose, and interviews. According to Lacan's theory of the "mirror stage," an infant recognizes its own image and realizes that the world is a separate entity and enters the symbolic order, or the social structures that accompany linguistic communication. This split between the "self" and "Other" within the subject's identity nullifies Snyder's depiction of an enlightened mind, where the "dualistic" constructions of subject and object cease to exist (171).

In order to challenge Dean's reading of the Coyote, I base my argument on two assertions. The first relates to Snyder's contextualization of the mythical animal from his writings and interviews. The second involves my reading of the last verse as an allusion to Dōgen's second aspect of enlightenment. Snyder, who has referred to himself as a "Buddhist-Shaman," believes that the Coyote figure should not be restricted to its usual Native American context (Real Work 156). In a 1979 interview with Michael Helm, Snyder reveals the universal quality of the Coyote when he says, "The trickster is an archetype inside all of us. There's no cultural monopoly on any of this" (156). In The Old Ways, he reveals a "nondualistic" aspect to the trickster figure in which "there wasn't a clear dualism of good and evil established there" (84). His perception of the mythological figure greatly conflicts with Dean's reference to the Coyote as a "beast" with some "hauteur." In "Piute Creek," Snyder, like the poet Robert Duncan, does not appear "interested as much in the truth of the myths or in the imaginative coherence they 
provide," but rather their use as "expressions of numinous awareness" (Altieri, "Book of the World" 87). In my reading, the uncharacteristic tame behavior and admiration of the Coyote complement rather than interfere with the profound awareness that accompanies the Void.

\section{Allusion to Dōgen's Enlightenment}

The final line, "Watch me rise and go" symbolizes a spiritual transformation (29). The Coyote's presence as an observer deepens Snyder's portrayal of the Void. For Dean, this verse connects the mythical figure with the subject and provides the foundation for the fracturing of the subject's identity. As this section will illustrate, my interpretation of the final verse, containing the poem's only personal pronoun ("me"), as an allusion to Dōgen's articulation of enlightenment, strengthens the aesthetic of "nonduality." While the "Cold proud eyes" of the Coyote recognize the subject's unique consciousness, they are also "unseen" (27). In contrast to Dean's argument that the subject becomes "aware of itself as object of another's watchful gaze," I assert that the Coyote's presence accentuates Snyder's void and his ephemeral presence goes undetected by the subject (170). The shape-shifting characteristic of the mythical figure creates the possibility of a non-reciprocal gaze.

The verse "Watch me rise and go" alludes to the second aspect of Dōgen's enlightenment where the body and mind "drop off" (29). As a result, the phrase "Watch me" acts as a rhetorical gesture aimed at the reader, rather than an acknowledgement of the Coyote in the poem. The personal pronoun signals a blatant ego-centered mind that contradicts the Void. However, the aesthetic of "nonduality," which represents the 
dissolution of "dualistic" formations such as "self" and "other," overwhelms the connotation of a self-centered "transcendental elevation" that commonly occurs in the Transcendentalists' writing. The mythical figure's presence does not disturb, but rather reinforces the Zen state of consciousness. Throughout his poetry, Snyder's shaping of the Void often involves suppressing personal pronouns, except when their dual meanings strengthen Buddhist aesthetics.

In "Piute Creek," the intrusion of the overtly dramatized subjectivity disrupts the objective tone. Illogicality is a Zen trademark that is intended to short-circuit the rational mind - the tyranny of language - and lead the prepared mind to an immediate "nonverbal" confrontation with reality (Hori 282). Haiku and the koan are integral to the Zen meditative practice that seeks to evoke "paradoxes which defy logical resolution and invite a different sort of perception, an awakening" (Soulsby 6). To circumvent the conventional meanings of words, paradoxical and unconventional approaches to language and speech are integral to Zen's aim of "direct intuition." As the poem switches to an objective tone with the arrival of "A clear, attentive mind," Snyder's void embodies the Buddhist concept of "no self" (19). Nolan Pliny Jacobson's definition of "no self," from his book Understanding Buddhism, exposes a pronounced incongruity between the use of the personal pronoun and the context of the Void. He writes, "Nothingness in Buddhism is a positive notion, an attempt to convey knowledge about an existent that can be understood only when the self has been abandoned and a substance-based orientation is given up" (78). Snyder's trademark pattern of interrupting Zen states of consciousness through the use of the personal pronoun in the final lines of his poems often indicates a radical hermeneutic tactic. 
The dramatic subjectivity in the last line contrasts drastically with the established aesthetic of "nonduality." The enlightened subject is suddenly connected back to the ego-centered consciousness in the first stanza. This contradiction resembles the characteristics of a Zen koan which Snyder became extremely familiar with through his Rinzai practice and studies. The suppression of the personal pronoun "me" until the final line suggests a blatant egoism that turns farcical in relation to the overarching Buddhist concepts of "no self" and "nonduality."

The metaphoric leap in consciousness immediately before the stanza break and the symbolic spiritual ascension that ends the poem fit Dōgen's "two aspects of enlightenment" (Glass 70). Buddhist enlightenment occurs through a sudden "awakening" that prefaces the realization of the Void. The awareness that arises with enlightenment results in "experiencing the truth before logic, intellect, and verbalism cut it off from its living source" (Soulsby 13). According to Dōgen, the first aspect of enlightenment that Buddhist practice realizes is "cutting the root of thinking" (Glass 70). Snyder represents this stage by turning "words and books" into a "small creek" that drops off and disintegrates in the air (16-18). This first aspect requires "sitting, which severs the root of thinking and blocks access to the road of intellectual understanding" (Glass 70). The second, more difficult aspect of enlightenment results in the "dropping off of body and mind" (70). This experience appears to parallel the dissolving of the subject/object binary. The second aspect of enlightenment culminates in the last verse, "Watch me rise and go" (29). At this moment, the body is 'dropped' and with it, one 'lets go' of delusional linguistic and mental representations that assail ordinary consciousness. 
In an interview with Paul Geneson in 1976, Snyder reinforces Dōgen's articulation of enlightenment, while also elucidating the relationship between poetry and the "self." He states, "And to express all of our selves you have to go beyond your own self. Like Dōgen, the Zen master, said, 'We study the self to forget the self. And when you forget the self, you become one with all things"' (Real Work 65). My reading of the last verse as an allusion to Dōgen's second aspect of enlightenment rests on the dominant aesthetic of "nonduality," which substantiates the Void and invalidates an ego-centered "transcendental elevation." The Zen state of consciousness in "Piute Creek" entails the dissolving of the duality of body and mind into 'oneness,' thereby contesting Dean's construction of the subject's fractured identity.

Since an encounter with the Void occurs as a "non-verbal" experience, the poem ends by taking the reader to the edge (razoredge) of Buddhist "emptiness." The ensuing flight of consciousness is witnessed by the powerful mythical Coyote or "Trickster" that influences Native American ultimacy. The Coyote's docile behavior and admiration show it to be a mythological counterpart to the enlightened subject. The mythological figure watches approvingly as the subject figuratively goes beyond the animal's mystical presence and completes the experience of the Void. This interpretation of the Coyote reflects Charles Altieri's view that myths can serve as "expressions of numinous awareness" more than "truth" or "the imaginative coherence they [myths] provide" (Altieri, "Book of the World" 87). However, the anthropomorphic Coyote's presence still represents the projecting of human-perceived reality onto the non-human world, a rhetorical device known as the "pathetic fallacy." This juxtaposition of Native American 
and Buddhist ultimacy slightly diminishes the aesthetic of "nonduality," since relativizing súnyatā conflicts with its status as unobjectifiable.

Despite weaknesses in Snyder's immature portrayal of the Void, such as the brief didactic tone and use of the "pathetic fallacy," the aesthetic of "nonduality" dominates the second stanza. My reading of the Coyote, where the animal's presence does not enter into the awareness of the poem's actor, and the allusion to Dōgen's enlightenment in the last verse, nullifies Dean's fracturing of the subject's identity. Ives' description of śūnyatā fits the developing Buddhist perspective in "Piute Creek": "Shifting from dualistic subjectivity, one undergoes a liberating expansion into the open field of experience in which what appears to be the 'self' and what appears to be an 'other' have been dwelling all along" (21). Although contradictions exist in Snyder's void, the aesthetic of "nonduality" supersedes Dean's misreading of the relationship between the Coyote and the subject.

\section{The Sublime}

Dean's marginalization of Zen practice and Buddhist discourse surfaces in a remark that reveals a view of the West as hierarchically superior to the East. He says, "Another name for some instances of Zen-like conditions and attitudes as they get figured in Riprap and elsewhere is the sublime" (159). Building on the subject's disfigured identity, he asserts that a purely subjective perception has been established. Then, through his application of the Kantian sublime and contemporary theorist Neil Hertz' modifications to Kant's ideas, he reduces "Piute Creek" to a Transcendentalist text. 
The purpose of examining Dean's reading of "Piute Creek" as a transcendentalist text is not to compare the subject's consciousness with the Western idea of the sublime, but rather to show that his reduction of the poem conceals Buddhist aesthetics. In order to accomplish this objective, I will briefly elucidate the core of Dean's version of the sublime. While a Buddhist perspective ironically places the East hierarchically above the West, I do so with the aim of creating a more comprehensive vision of Snyder's poetry, which requires both Eastern and Western models.

Dean's premise that forms the subjective bond between the Transcendentalists and Snyder rests upon Immanuel Kant's fundamental idea that "Sublimity, therefore, does not reside in anything of nature, but only in our mind" (160). This view of human perception contrasts greatly with Snyder's view of "the whole universe as interconnected, interpenetrating, mutually reflecting, and mutually embracing" (Riprap 65-66). In addition, Snyder's poetic declaration "all change, in thoughts / As well as things" from the poem "Riprap" reinforces a fundamental difference between his perception of reality and that of the Transcendentalists (32). These final two lines of the poem reflect an absolute, all-encompassing reality where change occurs through subjective perception, but also in the objects themselves. Snyder's idea of the "self" and "other" interpenetrating drastically differs from the Transcendentalist's stress on interpreting nature.

Based on Dean's rendering of the subject's perception as purely subjective, Dean surmises that a "dualistic" gap between subject and object exists within the identity of the poem's actor. He then forms a connection between the fractured identity and the sublime: "What I am suggesting is that the identifications precipitative of sublime affect 
as I have described in Snyder's poem ... are something like mistakes - mis-takes, images improperly taken to represent something other than that which they are" (171). After adding this idea of an unreliable reflective consciousness to the sublime, Dean turns to Hertz' recent analysis of Kant's work to strengthen the disfigurement of the subject's enlightened consciousness. Hertz makes the following observation about the sublime: "the mind's confusion at the point of blockage depends upon the plurality of the object, its seeming inability to be synthesized, which thus confirms subjective unity (the one unable to grasp the many precisely because of its unicity) (161). The idea that "blockage" accompanies the sublime intersects to a certain degree with the Buddhist notion that the senses and ego collapse during the enlightenment. However, the differences are striking beyond this initial intersecting of the Eastern and Western models of perception.

On a deeper level, the multifaceted Void accounts for the simultaneous plurality and singularity of objects quite differently than Hertz. The "inability" of Hertz' model to "grasp the many precisely because of its unicity" reveals a limit of the Western conception of the sublime in critiquing Buddhist ultimacy (161). Furthermore, the moment of "blockage" that occurs when "the mind's capacities are temporarily stymied by the object" forms a striking dissimilarity with the liberated consciousness that arises with aesthetic of "nonduality" (161). Snyder's visionary moment in "Piute Creek" represents an opportunistic experience to liberate the self from a "dualistic" perception of the world. Dean's version of the sublime conflicts with the unified consciousness of the Void and subsequently forges a bond between "Piute Creek" and the dramatized subjectivity that imbues Emerson and Thoreau's poetry and prose. 


\section{Snyder and the Transcendentalists}

Although Kant's construction of the sublime exists solely in the mind, he also stressed the limits of apprehending reality and truths through subjective perception (Oelschlaeger 115). Despite his caution, the Transcendentalists took an absolute view where nature is symbolic of the divine spirit. They relied on a special form of "intuition" and Emerson even warned that transcendental experience "demands something godlike" (Ellwood 56). Although the writings of Emerson and Thoreau frequently mirror Hindu and Buddhist principles, the intrusion of their subjectivity within the Western religious framework imbued their with writing varying degrees of anthropocentrism. The Transcendentalists' style contradicts Snyder's Buddhist themes of "interdependence" and the aesthetic of "nonduality." The allusion to Dōgen's Zen philosophy and Snyder's skill at converting the aesthetics of Eastern poetry into contemporary Western poetics are integral to avoiding a self-centered mystical experience of nature. For Snyder, being associated too closely with the Transcendentalists' poetry or imaginative prose jeopardizes his eco-political stature as the equiniminous "voice from the wilderness, my constituency" (Turtle Island 106).

Although Emerson, Thoreau, and Snyder's desire for solitude in nature ultimately turns the land into a mythic space where individuals can find their true selves, their approaches are distinctly opposed. Snyder's effort to organize experience through inward meditation and contemplation differs from the Transcendentalists' paradoxical strategy of fixating on visionary moments in nature only to transcend them (Dean 170). Dean calls this latter model "sublime transcendence" (170). He explains that the prerequisite for this 
model is isolating one's self in nature: "The Nature of the Transcendentalist thus begins to look like a phantom, something to be passed through and beyond, but which yet remains so insubstantial that no substantive 'beyond' exists (38). The quintessential example is Emerson's passage from the essay "Nature," which Harold Bloom calls "the most American passage that will ever be written" (Selby 4). Emerson states:

Standing on the bare ground - my head bathed by blithe air and uplifted into infinite space - all mean egotism vanishes. I become a transparent eyeball; I am nothing; I see all; the currents of the Universal Being circulate through me; I am part or parcel of God. (4)

Emerson's Western notion of God resonates with the spirit of Hinduism and Buddhism. As the land is transcended, "egotism vanishes," and subjectivity figuratively dissolves (4). However, the Eastern religious tone is eclipsed by the excessive repetition of "I," which brings acute awareness to Emerson's subjectivity and his hierarchical position in nature. This contradiction is emblematic of the Transcendentalists' ideal of deriving divine meaning from experiences in nature. Snyder's portrayal of an unenlightened mind in the first stanza fits Dean's version of the sublime, but diverges from his "sublime transcendence" model after the spatial ellipsis that denotes "emptiness."

Snyder's poetry often redirects the focal point of visionary moments in nature to the land through transcendence of the "self," which differs in subtle ways from Emerson and Thoreau's "transcendental" experiences. Riprap's "Piute Creek" is no exception. His koan-like verse pertaining to rocks in the midst of the "nondualistic" realm of the Void exemplifies this pattern. Dean appropriately observes that Snyder's "poetic vision serves always to direct attention back to the ground" (36). The poem reflects Riprap's 
emphasis on metonymy and literalness, which serves to convey the substantive meaning of objects like rocks. This style complements Snyder's view of Zen but diverges significantly from the prominent use of metaphor by the Transcendentalists. Julia Martin expounds on this idea when she comments on Snyder's poetry: "It should be clear that he has good reason to be wary of the kind of metaphoric transfer that appears in the writings of many Western mystics, and of the metaphors and symbols characteristic of so much Romantic and Modern poetry" (101-102). In addition to the lack of metaphors, the suppression of personal pronouns, compression of Chinese and Japanese poetry, and nondescript imagery, also fit Riprap's style and shape the non-transcendental tone of "Piute Creek."

Despite significant differences, Dean pursues his characterization of Snyder as a Transcendentalist and reconciles "Piute Creek" to the "sublime transcendence" model (170). Dean shows that the Transcendentalists' paradoxical strategy of fixating on visionary experiences in nature in order to transcend them conceals metaphysical uncertainties and anxieties involving the relationship between the land and identity. He states that "Snyder resolves this paradox by refusing transcendence, a refusal which bears as its corollary the displacement of the mind of man from universal centrality" (36). Rather than engage or assimilate an alternative view of reality outside Western philosophy, Dean forces a reconciliation of Snyder's idiosyncratic Buddhist poetics to his notion of "sublime transcendence." The quotation above reveals his certitude that visionary moments in nature, such as Snyder's articulation of the Void, either adhere to or violate the prominent formulaic expression of "transcendence." Dean 'displaces' Snyder's poetic ideal of bringing the reader to the "razoredge" on the grounds that it is 
"other" than Dean's idea of the "mind of man" - which exists within his idea of "universal centrality" (36).

A final observation that substantiates Snyder's predilection for unconventional stylistics and creative allusions involves the title - "Piute Creek." Snyder's choice of water, which predominantly symbolizes the flux of nature in his poetry, upsets the conventional model of Transcendentalism where solid ground (or "bare ground" in the earlier Emerson passage) is transcended. The point is accentuated by Dean's remark regarding "Riprap's" style. He states, "In this poetic scheme, the figural is literalised, the image literally concretized. That is, in its conclusion, 'Riprap' focuses attention on the rock as that figure of substantiality which may ground the world" (188). In "Piute Creek," immediately before encountering the Void in the second stanza, Snyder transcends the "ground." However, the ground is paradoxically water - and imaginary since it elevates off a ledge. He writes, "Like a small creek off a high ledge / Gone in the dry air" (17-18). Then, amidst the elevated consciousness of the Void, the focal point returns to the solidity of rock with the koan-like verse: "No one loves rock, yet we are here" (22). Both this verse and the title exhibit the illogicality and paradox that Zen embraces.

\section{Conclusion}

For Snyder and the Buddhist tradition, true understanding of reality lies in experiencing a consciousness that repudiates the Cartesian duality. By examining "Piute Creek" from a Buddhist perspective, I have attempted to reveal a dominant aesthetic of "nonduality" that supersedes Dean's misreading of the Coyote. Although part of 
Snyder's representation of the Void includes an uncharacteristic metaphor, he counters the trope with his idiosyncratic Buddhist poetics. The poem conveys a nontranscendental tone and effectively communicates concepts like "no self" and "nonduality." These features of Snyder's poetry expose the flaws in reducing "Piute Creek" to a Transcendentalist text.

While Dean's in-depth study of Snyder's poetry reveals many new insights, his marginalization of Zen practice and Buddhist discourse reveals a privileging of Western thought and literary models. The following sentence from his book Gary Snyder and the American Unconscious supports this assertion: "[T]he emphasis on Buddhism (and the East) obscures the central importance of Snyder's work for mainstream American culture (and the West)" (Notes 218). Like Charles Altieri's application of the "poetics of presence" in the poem "Sixth-Month Song in the Foothills," Dean underestimates the vital importance of Buddhist aesthetics and philosophy in "Piute Creek." Without at least orienting Snyder's poetics within the Void, Western literary and philosophical models inevitably miss the Buddhist content and intricate interconnectedness that make his poems unique. 


\section{CHAPTER IV}

\section{BRINGING THE EAST TO THE WEST THROUGH 'DISRUPTION'}

\section{Introduction}

Thirty-seven years separate Gary Snyder's first published book, Riprap, and his opus work called Mountains and Rivers Without End, which is named after a Chinese scroll painting. Although the collection of thirty-nine long poems formally began in 1965 with the publication of Six Sections from Mountains and Rivers Without End, the longawaited book had been brewing since it was first mentioned in Jack Kerouac's Dharma Bums in 1958 (Dean xv). The novel provides an account of Kerouac and Snyder's adventures as "Zen lunatics," and is loosely based on real life experiences. The fictional Japhy Ryder (Snyder) tells Ray Smith (Kerouac):

Know what I'm gonna do? I'll do a new long poem called "Rivers and Mountains Without End" and just write it on and on on a scroll and unfold on and on with new surprises and always what went before forgotten, see, like a river, or like one of them real long Chinese silk paintings that show two little men hiking in an endless landscape of gnarled old trees and mountains so high they merge with the fog in the upper silk void. (200) 
Mountains and Rivers includes previously published poems and encompasses Snyder's passion for Asian art forms, Native American mythology, the practice of Zen, and the interrelationship of Buddhist philosophy and nature. The last poem, "Finding the Space in the Heart," is ninety-eight lines and includes a lengthy rendering of the Buddhist Void. The poem represents a compelling example of transforming Buddhist philosophy from abstract metaphysical discourse into images and ideas. This outcome significantly enhances the aesthetic of "nonduality" and potentially improves the reader's perception of the "razoredge."

Snyder's void in "Finding the Space" reinvigorates old techniques and styles. In the process of introducing creative new strategies, he also freely undermines longestablished methods in what is perhaps his final vision of Buddhist ultimacy. In this chapter, I begin by exploring the creative combinations of anthropomorphism and metaphor that undermine Snyder's dominant "riprap" style. Second, my analysis will look at how the poem radically disorients the reader through a technique that adheres to Zen's "rhetoric of disruption." This strategy creates the potential for a suspension of interpretation which strengthens the aesthetic of "nonduality." Lastly, I argue that Snyder communicates the Void in "Finding the Space" through techniques that resist French Deconstructionist Jacques Derrida's destabilizing of binary pairs.

\section{Riprap / Myths and Texts}

Understanding Snyder's use of similes and metaphors provides valuable insight into the evolution of his shaping of the Void. The early formation of metaphor in his poetry begins with Myths and Texts (1960), the writing of which overlapped with Riprap, 
published one year earlier (Murphy 22). Snyder's undergraduate thesis written in 1951, which combines first-hand knowledge of a Native American myth and of anthropological theory, provides the backbone for the mythopoetic poetry in Myths and Texts (Dean xiii). The book reflects the dynamism of universal archetypes and oral traditions of dead and living cultures. The diverse range of mythological figures from Buddhism and Native American culture conjoin to create a dramatic setting that is rich with metaphor. For example, in "Burning 2," the void takes on dark, menacing qualities of the mind: "[W]here the sword is kept sharp / the VOID / gnashes its teeth" (38). The line also names the Void, a practice that is avoided in later works since the term represents a consciousness that is unnamable through "dualistic" thinking and language.

In Myths and Texts, Snyder draws on dynamic mythology to convey the idea that Zen states of consciousness require a fierce struggle. In the verse from the above paragraph, the sword, which fittingly includes "word" within it, serves as a metaphor for the sharp, disciplined mind associated with Zen training. The metaphorical imagery in the book also amplifies the adventures of Buddhist figures like Maudgalyayana. However, the regular juxtaposition of classical mythological images and emphasis on oral poetry eclipse any possibility for conveying "direct intuition." The tone of Myths and Texts differs remarkably from Riprap, where substantial shifts in consciousness take place with less effort and tension. Riprap's emphasis on literalness and metonymy became Snyder's preferred style for representing Zen's inner awareness of the self.

While Myths and Texts expresses a vibrant atmosphere with exaggerated exploits on the part of the hero-poet, the steadfast intensity disappears in Snyder's ensuing works. The suppression of metaphor in his poetry coincides with the influence of Modernism on 
his poetic style. The drastic stylistic change shapes his poetics for the next four decades. The poetic initiative in Riprap suppresses metaphor and frequently omits articles and adjectives to express the concreteness of objects and ideas. This characteristic aligns with Modernism's proclivity for altering forms and breaking down prevailing boundaries. Riprap turns away from the energy of Myths and Texts to a calmer, more subdued expression of mind and nature. The opening lines from "Riprap" illustrate the stylistic change: "Lay down these words / Before your mind like rocks" (32). Snyder takes great care to restrict the use of metaphor in many of his early works, particularly when expressing the Void.

A significant facet to Snyder's void in "Finding the Space" relates to a longstanding problem about how to communicate Zen states of consciousness. The disagreement involves perhaps the two greatest Mahayana Buddhist philosophers, though they lived in different times. Nāgārjuna, an Indian philosopher (c. 150-250 C.E.), relied on the Sanskrit language and his laconic dialectical style to convey "nonduality" (Loy). Although Nāgārjuna's work predates Zen, his ideas and philosophy continue to have a profound influence on the way modern schools teach Zen and Buddhism. For Dōgen, a Zen master and philosopher, his approach was rooted in the ideographic Japanese language and he displays an affinity for simile and metaphor (Loy). Both philosophers attacked the opposing style by relying on the flexibility of Buddhist philosophy and discourse. Snyder frequently references their works through allusions and direct references. Today, Zen philosophers continue to debate whether a rational literal emphasis on language or an approach based on metaphorical tropes serves as the best instrument to answer the metaphysical questions that face Buddhism. Although Snyder's 
"riprap" style is more closely aligned with Nāgārjuna's writing, he shows in "Finding the Space" that Dōgen's reliance on metaphor becomes relevant in his expression of the Void.

\section{A Buddhist Perspective on "Finding the Space"}

In "Finding the Space," the creative techniques for conveying Buddhist philosophy through language take shape against a casual matter-of-fact tone. The undemanding shift from an ordinary consciousness to the realization of the Void is subdued even in comparison to Riprap's style. The change suggests an inclination toward evoking spontaneous ongoing insights instead of rendering a sudden experience akin to "direct intuition." Rather than show the subject's transformation from an "unenlightened" mind to an "enlightened" one, the Void is presented as always available. The direct expression of siunyatā is contained in the entire eleventh and twelfth stanzas, but a portion of the tenth stanza reveals the crucial atmosphere that prefaces the Zen state of consciousness:

let the car coast to a halt on the crazed cracked flat hard face where winter snow spirals, and summer sun bakes like a kiln.

Off nowhere, to be or not to be,

all equal, far reaches, no bounds.

Sound swallowed away, no waters, no mountains, no

bush no grass and

because no grass

no shade but your shadow.

no flatness because no not-flatness.

no loss, no gain. So-

nothing in the way! 
- the ground is the sky

the sky is the ground,

no place between, just

wind-whip breeze,

tent-mouth leeward,

time being here.

we meet heart to heart,

leg hard-twined to leg,

with a kiss that goes to the bone.

Dawn sun comes straight in the eye. The tooth

of a far peak called King Lear.

Now in the nineties desert night (52-78)

At the poem's start, Snyder and his traveling party began in the sixties. They travel down from Canada through San Francisco to a desert-and into the nineties. Here, unlike in previous depictions of the Void, Snyder's presence seems detached from the poem's "nondualistic" perception. It is as if the reader can easily step into the position of the poem's subject or any of the would-be passengers in the car. The randomness of the experience fits with the Rinzai Zen notion that an "enlightenment experience occurs in an instant and can come at any time" (Disanto, Steele 128-129). In addition, the mountains and the wild of the Pacific Northwest that provide the usual background for his poems give way to the emptiness of the desert.

In the final poem of this long-awaited book, the desert provides an unlikely setting. The barren landscape combines with Snyder's characteristic nondescript scenery to turn the desert into an ideal symbol of the Void or "emptiness." Chapters two and three reveal Snyder's integration of various attributes of the Zen koan. Traditionally, the koan works when a Zen master delivers a puzzling question, which over time, triggers a "direct intuition" in the student. Snyder draws on the koan's capacity to produce an "experience said to be prior to conceptual reflection," in order to enhance the reader's 
perception of the "razoredge" (Crittenden 56). As my analysis of "Finding the Space" will show, the poem consists of multilayered meanings, some of which require a gradual unfolding to communicate Buddhist philosophy. This tactic resembles Rinzai Zen's counterpart, Soto Zen, which teaches that "enlightenment occurs little by little over a long period of time" (Disanto, Steele 128).

The line that precedes the Void in "Finding the Space" conveys an image that differs greatly from the "transcendental" verse that prefaces śünyatä in "Piute Creek." In the latter, the image of a metaphorical flight off a ledge leads to a drastic shift in consciousness; the simile "Words and books / Like a small creek off a high ledge / Gone in the dry air" distinguishes an unenlightened mind from an enlightened one (16-18). In "Finding the Space," the simple line "summer sun bakes like a kiln" leads up to the Void. Then, the scorching sun of the desert is linked with the coldness of the mountains, blurring the boundary between seasons: "winter snow spirals, and / summer sun bakes like a kiln" (55-56). The simple image is far removed from a troubled mind experiencing a spiritual ascendancy. The triteness of the simile hints at a less serious commitment on the part of the reader and an avoidance of difficult Buddhist discourse.

Another distinguishing feature of this version of Snyder's void is that the Zen state of consciousness does not seem mediated by Snyder, but rather a "nondualistic" realization in and of itself. "Emptiness" is open to anyone who connects with the simplicity of the simile. The next verse "Off nowhere, to be or not to be" presents an obvious allusion to Hamlet (57). The verse fits the carefree and simple tone set in motion by the simile. The accessibility differs considerably from "Piute Creek's" evanescent images of śünyatā as "Night chills. A flick / In the moonlight / Slips into Juniper 
shadow:" (23-25). On the verge of the Void, Snyder accentuates the already existential tone of Shakespeare's line by following it with a spatial ellipsis.

Snyder's previous portrayals of Buddhist ultimacy often derive from a fleeting moment with intense imagery, which can cause the experience to appear mystical and religious. Rather than focus on conveying a "non-verbal" experience in "Finding the Space," Snyder stresses a gradual process of negation and the creative application of past aesthetic choices. The lengthy depiction of the Void first relies on unconventional grammar in the eleventh stanza, then switches to imaginative images in the twelfth stanza. I refer to the former style as a "non-rational-but-logic-oriented" strategy to capture the embedded Buddhist philosophical ideas in the poem. Snyder's use of nonrational and unconventional schemes closely resembles Zen's "rhetoric of disruption." Like the koan, "the rhetoric of disruption" is designed to disorient, cut "through ordinary experience and thus also ordinary linguistic forms" (Wright 96). Snyder's statement about Zen's ability to tear "yourself out of your personality and your culture and putting yourself back in it again" echoes the premise of the "rhetoric of disruption" (Real Work 4). He blends the previously dominant objective "riprap" style with the seldom-used tropes of metaphor and anthropomorphism to convey the Buddhist concepts of "interdependence," "nonduality," and "co-dependent arising."

The first line of the indented eleventh stanza establishes the idea of Buddhist "nonduality:" "all equal, far reaches, no bounds" (58). The verse intimates an unconditional equality and a lack of boundaries that foretells a geographic, as well as a psychic expression of śünyatā. Buddhist "nonduality" pertains to a perceptive change that arises with the Void, in which the notion of subject and object within the "self" 
dissolves. This poem presents the subtleties of this concept by using nondescript images of nature as the backdrop for conveying Buddhist philosophy and discourse. However, Snyder improves on communicating the aesthetic of "nonduality" by radically disrupting the reader's ordinary perception of images and ideas. The first indication that the poem intends to disorient occurs when Snyder exchanges the usual symbols of his home turf, mountains and rivers, for the flatness of the desert.

Snyder begins disrupting the Western idea of boundaries by leaving a dangling "no" and the conjunction "and" at the end of the third and fourth lines of the eleventh stanza: "no waters, no mountains, no / bush no grass and" (60-61). The unfinished end leaves the reader grasping for the next word to finish the thought. This technique reaches its climax when the adverb "just" abruptly ends the eleventh stanza and visually drops into the "empty" space before being completed in the next stanza. The structural spacing heightens the dramatic incompletion and adds to the aesthetic of "emptiness." This strategy of ending lines with dangling words visually and linguistically illustrates the Buddhist concepts of "interdependence" and "co-dependent arising." The technique also fits the "rhetoric of disruption," which claims to bring about an "immediate, prereflective response" that shocks the self "out of the ordinary and into an open space where one's prior socialization is rendered dysfunctional" (Wright 97). Snyder employs a variety of tactics to disrupt the conventional use of structural boundaries and English grammar.

Through his idiosyncratic Buddhist poetics, he repeatedly shows geographic boundaries to be illusory. The strategy of negating the landscape plays a pivotal role throughout Snyder's void. Dale Wright, Professor of Religious Studies at Occidental College, notes that "In many classical Zen narratives, disruption and disorientation are 
hastened through the use of negative language, which disrupts conventional practices and beliefs" (98). Snyder negates the imagery of "waters," "mountains," "bush," and then the "grass" to reduce the land to "emptiness." Ironically, Snyder negates objects that frequent his native landscape and ordinarily play a role in his portrayal of Zen states of consciousness. In the final four lines of the eleventh stanza, Snyder reverses the pattern of negation:

nothing in the way!

- the ground is the sky

the sky is the ground, no place between, just (66-69)

The two affirmative assertions in lines sixty-seven and sixty-eight blur the boundary between the sky and ground. This technique of negation followed by affirmation bears too strong a resemblance to the Buddhist text "Heart Sutra" to be coincidental:

Form does not differ from emptiness;

Emptiness does not differ from form.

Form itself is emptiness;

Emptiness itself is form. ("Heart")

Snyder shares the same strategy as the famous passage, but the latter focuses on "emptiness" rather than nature.

The twelfth stanza exemplifies the complex Buddhist idea called "co-dependent arising." The term refers to the notion that all phenomena are said to be inherently empty of essence because things always "co-arise" in the world. Wright explains "codependent arising" as a condition where an "entity 'originates dependent' upon other entities ... the entity therefore lacks 'own being' .... The thing is not self-determining; on its own it would have never come to be what it is" (51). This intricate concept is 
construed through word clusters and syntactical devices such as hyphens, as well as the unexpected inclusion of metaphor and anthropomorphism:

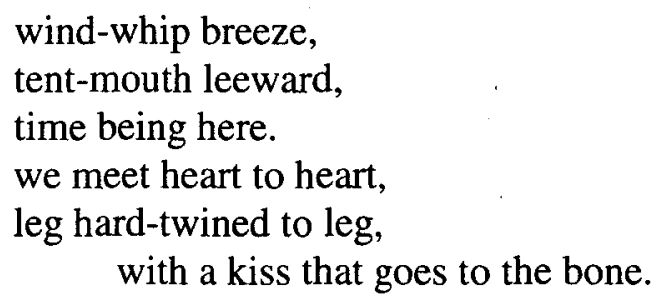

Now in the nineties desert night (70-78)

The first line in the twelfth stanza plays with the properties of the wind and adds to the hazy boundary between the ground and sky. The hyphen connects the noun "wind" with the verb "whip" to create a complex type of breeze which dislocates the dominant position of the wind. The creative linguistic connection relies on metonymy to produce the verse's original meaning. Literary critic Tim Dean describes this tactic as follows: "[T]he placing of elements juxtapositionally ... resists the hierarchic structure of metaphoric meaning and symbolisation" (188). The word clusters and hyphens in this poem convey "co-dependent arising" by illustrating an acute dependence and a lack of independent essence. "Co-dependent arising" forms a vital component of the principle of "interdependence" or pratītya samutpāda - both are inseparable aspects of the Void.

The second line of the twelfth stanza contains another hyphenated image that connects with the previous unique description of the wind: "tent-mouth leeward," (71). The tent itself insinuates that a human presence is dwelling in the Void, but Snyder remains detached and resists filtering the experience through his perspective. Giving the tent a human characteristic begins a theme of anthropomorphism that combines with an uncharacteristic extended metaphor. The metaphor of the body signifies a human's 
presence meeting the Void "heart to heart" (72). The anthropomorphism continues as the heart connection between the human body and the Void expands with the image of "a kiss that goes to the bone" (74). The mixing of the sensual with the body's hard unseen structure represents a symbolic union of internal and external realms. This image accentuates the idea of "interdependence." Throughout the poem, a vivid sexual union develops through sensual imagery and fuses with the symbolic rendering of siunnyatā. This sexual dynamic adds another layer to the complexity of Snyder's void.

The depiction of the Void ends with the two lines, "Dawn sun coming straight in the eye. The tooth / of a far peak called King Lear" (76-77). The "summer sun" that initiates the encounter with the Void forms a connection with the image of the "Dawn sun" that closes the poem $(56,76)$. Unlike the bodily metaphor that shapes the Void through vivid imagery, the metaphoricity in the penultimate verse is effective not because of its transcendental quality, but ironically, because it depicts the radiant sun more precisely and economically than any literal depiction might. Then, the last line reveals that the sun is perhaps reflecting off a mountain peak. The image of the sun coming "straight in the eye" as opposed to reflecting off a mountain underscores the illusory nature of language (76).

The end of the twelfth stanza also incorporates metonymy, with the "tooth" of "King Lear" acting as the name for a ridge below a far-off mountain peak. Snyder interweaves the extended metaphor of the body with the anthropomorphic Void and concludes the poem by introducing mountains into the landscape. The associations builtinto the Shakespearian reference to "King Lear" now form an indivisible bond with the image of a mountain peak. A reader may oscillate between the two distinct meanings, 
which reinforces the Buddhist principles of "interdependence" and "co-dependent arising." The shifting meaning of "King Lear" exemplifies the famous lines from the "Heart Sutra" that states, "Form itself is emptiness / Emptiness itself is form" ("Heart"). In other words, objects and ideas are inherently 'empty' as the principle of "co-dependent arising." Now, the Shakespearian character and the mountain ridge may be impossible to separate. The arbitrary linguistic connection potentially reveals the illusory boundaries of forms like the name "King Lear." In contrast to "Six-Month Song" and "Piute Creek," there is no personal pronoun to close the poem. "Finding the Space" ends more objectively with a subject only being directly inferred when the sun comes "straight in the eye" (76). Snyder uncharacteristically ends the portrayal of the Void with the tropes of metaphor and metonymy.

The image of the sun marks the beginning and end of the portrayal of the siunnatā. Likewise, the mountain peak "King Lear" connects back to the Shakespearean reference from Hamlet: "Off nowhere, to be or not to be" (57). This pattern reinforces a circular quality to the Void. In Buddhism, this resembles samsāra or the "Wheel of Life," which refers to the belief in the continuous cycle of birth, life, and death. Snyder echoes the idea of samsära when he says, "[b]ut there's also death, there's also the unknown, there's also the demonic. And that's the womb and the tomb, that's samsāra, that's birth and death, that's where the Buddhists go in" (Real Work 81). The initial meanings of the Shakespearian terms may change throughout the eleventh and twelfth stanzas, but the circular vision and matter-of-fact tone suggest that the Void is always available and more attainable than in previous poems. 
"Finding the Space" may represent Snyder's final decision on shaping the Void. The poem congeals two writing styles that reflect opposing Buddhist strategies, one that corresponds with Nāgārjuna's terse dialectical logic and the other with Dōgen's affinity for simile and metaphor, indicates Snyder's willingness to undermine his preferred "riprap" style to heighten the "rhetoric of disruption." Both philosophers share the fundamental goal of undermining ordinary linguistic thinking that fails to reveal ultimate meaning and the essence of Buddha's teachings. Nagarjuna's primary philosophical ideas are explained in the Mūlamadhyamakakārikā (Sanskrit for "Memorial Verses on the Middle Teaching")(151), which consists of twenty-seven short chapters made up of 400 rhythmic verses ((Diener, et al 149-150). Similar to the Zen koan, he relies on contradiction; the meanings are sometimes clear and sometimes they defy interpretation due to lack of insight into Buddhist discourse and practice. Snyder's non-rational-butlogic-oriented strategy in the eleventh stanza of "Finding the Space" closely resembles Nagarjuna's approach to Buddhist philosophy. Both styles avoid metaphor in their quest to evoke an intuition that unveils the limitations of linguistic dualisms. In contrast, Dōgen often drew upon images of "entangling vines," mountains, and even pictured cakes to "deconstruct dualisms" by creating "new ones" and inviting misinterpretation (Loy). Snyder references the pictured cake metaphor in blank and embraces metaphor in the twelfth stanza.

\section{Gary Snyder and Jacques Derrida}

Throughout the depiction of the Void, Snyder's idiosyncratic Buddhist poetics persistently break down the boundaries of opposing images and ideas. This strategy 
potentially strengthens the aesthetic of "nonduality" and subsequently the portrayal of the Void. The undermining of an arbitrary hierarchical value in a binary, such as "flatness" and "not flatness" in line sixty-four, corresponds with key elements in the

Deconstructionist thought of French philosopher Jacques Derrida. As I will show, certain aspects of Deconstruction coincide with Snyder's strategy of blurring "dualistic" boundaries and Zen's "rhetoric of disruption." The purpose of contrasting Snyder's poem "Finding the Place" with Derrida's deconstruction of binaries is to reveal the tension between "pure presence" as a symbol of the East and the skepticism that it faces in the postmodern thought of Western culture.

Snyder's disrupting of binaries like "flat"/"not flatness" and desert/mountain is a form of Deconstruction. The technique corresponds with Derrida's theory that all binary pairs have a dominant center that holds a structure in place. He reasons that the hierarchical binary structures that permeate Western thought are an illusion and extends this logic to conclude that "self-identity" and "consciousness-of-self" are misapprehensions (Derrida, "Structure" 887). This idea intersects with Zen's notion of a "dualistic" mind trapped in samsära, which Zen aims to alleviate through meditative selfdiscipline that leads to "direct intuition." Derrida's elaborate undermining of subjecthood reveals an individual's desire to experience "pure presence" or immediate meaning. Derrida uses the term "transcendental signifier" to describe an individual's preoccupation with a stabilizing center or truth. In Western culture, God exemplifies this concept of a 'perfect presence.' With regard to Snyder's poetry, the realm of the Void (beyond the dualism of binary pairs like absence and presence) satisfies the ideal of 'perfect presence.' In Derrida on the Mend, Robert Magliola shows that Derrida's key term 
"differance" corrodes "away any transcendental nucleus such as a Supreme Identity" (24). "Differance" refers to the French verb, which means both "to defer" and "to differ." The simultaneous actions of differing and deferral destabilize a structure's center.

When Derridean thought meets Snyder's void, certain aspects of deconstruction fail to deconstruct. In Of Grammatology, Derrida's pronouncement that "there is nothing outside the text" summarizes his position that language is a system of differences and meaning is always deferred to another "text" (158). Therefore, his deconstruction of binary structures destroys the possibility of Buddhist enlightenment that involves a "nonverbal" moment outside the structure of language. However, when Snyder's poetics are viewed from a Buddhist perspective, creative and unconventional schemes in "Finding the Space" complicate Derrida's process for deconstructing binaries.

The strategy of negation plays a pivotal role throughout the poem's portrayal of the Void. In the eleventh stanza, Snyder negates objects one by one until the plenitude of his native landscape turns into an 'empty' desert. As a result, the book's final poem rhetorically negates the title, Mountains and Rivers Without End. The process of negation reaches its height with the complex non-rational-but-logic-oriented agrammatical line that reads, "no flatness because no not-flatness" (64). The line demonstrates the illusory nature of opposites, as well as boundaries. An attempt to logically extract meaning through English grammar, reading it like a double negative, leads to the nonsensical assertion: no flatness because flatness.

The verse raises doubts about 'natural' opposites like "flatness" and mountainous or unevenness. The dominant position of the binary is dislocated. The koan-like line potentially forces a reader to think of "flatness" in new ways. The new ways complicate 
Derrida's deconstruction of binaries. Instead of altering the value of terms in the binary the line deconstructs the entire binary relationship. The verse epitomizes the "rhetoric of disruption" and creates the potential of temporarily resisting interpretation.

Snyder's miming of Nāgārjuna's logic allows "co-dependent arising" to prevent "flatness" or "not flatness" from becoming an absolute or "transcendental signifier." The poem reveals that things always "co-arise" in the world and the idea of "flatness" having an opposite is destabilized. In his essay "Word," Ryuichi Abe states that "Nāgārjuna's greatest contribution was perhaps his invention of a method to unleash the signifying power of words in order to reverse their illusory function" (297). "Flatness" co-arises with many things at once and so the idea of an independent essence is replaced by Buddhist "emptiness." "Finding the Space" ruptures the binary instead of the value of the opposite poles. Since Zen centers around silence, it is appropriate that Nāgārjuna's logic reveals linguistic categories to be illusions that always arise from "dualistic" language - words like all things are "empty." This point is crucial because Derridean thought evolved from logocentrism and must acknowledge that without the linguistic sign, the "structure" that Derrida destabilizes cannot be questioned. Therefore, any attempt to take deconstruction beyond logocentrism or language to a "nonverbal" realm is problematic. Snyder's verse borrows Nāgārjuna's logic to go beyond blurring the "dualistic" boundaries of a flat desert and mountainous terrain.

Although Derrida threatens the boundaries of all structures, he doesn't suggest that the hierarchies should be reversed. The intention of Derrida is to keep the structure in "play" and prevent another hierarchical binary from forming. Snyder's strategy based on Nāgārjuna's complex logic leads not to a questioning of the privileged and marginal in 
a binary, and not to a third alternative, but a deconstruction of the binary itself. Therefore, the danger of one binary replacing another as the dominant one is solved. Snyder does not advance a truth, but deconstructs the category of "flat."

Snyder's idiosyncratic Buddhist poetics reveal a method for resisting a permanent structure and getting outside the inherent "difference" that governs language. For Derrida, language is the foundation for meaning. This is the heart of schism between Snyder and Derrida. The former argues that the latter and his countrymen, are restricted by logocentrism:

Ninety percent of what all so-called humanists have done throughout history has been to fiddle with language: grammar and rhetoric and then philology ... And if some of the French are trying to take the Word apart right now, it's because they are in the same tradition with the same obsession. (A Place 82)

Snyder questions the ability of those who are "obsessed" with the "Word" to see outside the structure of language. When the "non-verbal" Void is conceptualized through language as a transcendental signifier, it fractures the Zen notion of "total presence" and weakens any vision of 'interpenetration' between Snyder and nature. However, Snyder not only shows that relationship of binaries like flat/mountain or presence/absence can be destabilized, but he ruptures the entire structure.

Snyder's equiniminous view of nature described in his essay "Blue Mountains Constantly Walking" illustrates what is at stake for him in this dispute. He says, "For those who would see directly into essential nature, the idea of the sacred is a delusion and an obstruction; it diverts us from seeing what is before our eyes: plain thusness" (Snyder, 
A Place 110). Snyder's status as spokesman for the nonhuman world depends on seeing past hierarchical structures. Derrida poses a threat to Snyder's "nondualistic" perception of nature since his destabilizations of binaries in his Deconstructionist theories lead to a fracturing of "pure presence."

While Derrida's intricate theories rely solely on cognitive abilities for success, Snyder's poetry and prose suggest his disciplined practice of Zen meditation leads to a liberation of the mind. Snyder's reinforces this point in Earth where he includes a translation of Zen Master Po-Chang Huai-Hai's life (720-814) and teachings (77):

The comrade asked "How do you get freedom? .... Such a man cannot be gathered in by either Heaven or Hell. Also, he doesn't read the sūtras and scan teachings; language should pliably return to oneself. All verbal teachings merely illuminate his present understanding of his own nature. (77)

While different Zen schools vary the emphasis on studying texts and meditation, Snyder appears to endorse the position that language provides only one means for knowing the world. Zen purportedly leads the "self" to absolute freedom from "dualistic" constructions that proliferate with linguistic communication, while deconstruction reveals that ontological claims are not valid "outside the text" (Derrida, Of Grammatology 158). "Finding the Space" shows that when you realize the "empty" nature of things, including linguistic labels like "flatness," the entire binary dismantles.

The most divisive difference between Snyder and Derrida arises because the former points toward a "non-verbal" perception of reality, and the latter recognizes only a reality within the "text," or system of language. Snyder's void depicts an ineffable spiritual experience, a reality beyond affirmation and negation. His poetry and Derrida's 
Deconstruction both aim to persistently break down the boundaries of opposing images and ideas. However, Snyder embraces the Buddhist idea that form and emptiness, like absence and presence, can exist simultaneously. Christopher Ives captures this thought through Zen philosophy: "As a logical and metaphysical term, śünyatā indicates both the lack of any independent essence or self in things and the interrelational dynamism that constitutes things" (2). For Derrida, this perception points to a destabilization of the transcendental signifier - this includes the Void. His radical idea of "making negative reference absolute" works by showing that a sign signifies only by what it is not, and is therefore endlessly deferred and destabilized (Magliola 24). In "Finding the Space," Snyder complicates this theory by revealing the binary of "flatness" and its 'obvious' opposite - unevenness - to be falsely imposed.

\section{Conclusion}

The deconstructionist perspective asserts that the referential nature of language eliminates the possibility of a totalizing arrangement of the world, God, or the Void. Derrida's logocentric theory therefore concurs with the West's skeptical view of "pure presence." However, Derrida's argument and potential for undermining Snyder's idiosyncratic Buddhist poetics is problematic since its footing is in speech and language or logocentric. This can be construed as a weakness from an Eastern point of view where ultimacy resides in silence or a "non-verbal" moment.

Derrida wrestles with the circularity of language or the "text" in his book Writing and Difference. He observes, "We have no language—no syntax and no lexicon-which is foreign to this history; we can pronounce not a single destructive proposition which has 
not already had to slip into the form, the logic, and the implicit postulations of precisely what it seeks to contest" (280). Derrida's Deconstructionist ideas are heavily indebted to Heidegger's attack on metaphysics. It is therefore interesting that Heidegger, referring to D.T. Suzuki, the most prominent authority on Zen in the early 1900's, stated that "[i]f I understand this man [D.T. Suzuki] correctly, this is what I have been trying to say in all my writings" (Glass 29). This statement was made in 1938 after Heidegger read Suzuki's Essays in Zen Buddhism.

Derrida's determination that "pure presence" is impossible is perhaps limited by the fact that language cannot escape the history of metaphysics and the system that produced it. Literary theorist Hazard Adams articulates this predicament by stating that "if everything is always already in the web of language, then there is nowhere to stand outside of language to employ the so-called object of discussion" (9). Snyder's idiosyncratic Buddhist poetics create the potential of a "nondual" understanding of the Void by turning the relativity and difference of language back on itself. The poem dismantles the linguistic tools as part of the negation process, perhaps bringing the reader closer to the "razoredge." 


\section{EPILOGUE}

\section{ACCEPTING 'RESISTANCE TO INTERPRETATION'}

\section{"Finding the Space in the Heart" and Postmodernism}

To conclude this thesis, the epilogue returns to chapter three's close reading of "Finding the Space in the Heart," perhaps Snyder's final vision of the Void. This section demonstrates that Snyder's void serves as an exemplary model for Thab Hassan's postmodern condition where an individual accepts all that goes "against interpretation" and embraces "misreading" (Harvey 44). The purpose is to reveal that the closer Snyder's idiosyncratic Buddhist poetics adheres to this postmodern notion of 'resistance to interpretation,' the more effective the aesthetic of "nonduality" becomes. My intent here is to spur innovative ideas by rethinking Western literary and philosophical models, and improve upon or create new methods for effectively understanding the Zen and Buddhist elements in Snyder's works.

In the twelfth stanza that ends the lengthy depiction of the Void, Snyder's overt use of metaphor and anthropomorphism contradicts his earlier suppression of them in The Back Country's "Sixth-Month Song in the Foothills" and Riprap's "Piute Creek." The "tent-mouth" begins a theme of anthropomorphism that merges with a highly uncharacteristic extended metaphor (71). Next, the subject's encounter with the Void is symbolized by a "heart to heart" meeting (73). The metaphor ends when Snyder's void is 
associated with a sensual kiss "that goes to the bone" of the subject (75). The extensive emphasis on metaphoricity contrasts with the previous stanza's stringent use of nondescript images. This idiosyncrasy disturbs the dominant position of the "riprap" style for conveying Zen states of consciousness.

Snyder's essay "Tawny Grammar," published one year before Mountains and Rivers' 1996 release, hints at a movement toward more expressive transcendental language. He writes, "Languages were not the intellectual inventions of archaic schoolteachers, but are naturally evolved wild systems whose complexity eludes the descriptive attempts of the rational mind" (A Place 174). His words imply an organic connection between nature and the infinitely complex forms of language. Throughout his poetry, Snyder consistently blurs the boundaries of images in nature and disrupts preconceived ideas to express Buddhist "nonduality." Indeed, by incorporating creative metaphorical strategies in "Finding the Space," Snyder even undermines his dominant "riprap" style. He also adds a new dimension to the Void when he intricately blurs the boundaries of linguistic ideas like the binary of "flatness" and "not flatness."

Snyder's current Zen outlook strengthens the aesthetic of "nonduality" since it destabilizes the literal/metaphor binary and the notion that an ideal style exists. To add to this revelation, the simplicity of the bodily metaphor in the twelfth stanza contrasts sharply with the non-rational-but-logic-oriented portrayal of the Void in the eleventh stanza. The merging of the literal and metaphoric, and sharp contrast between simple images and non-rational verses, adds to the destabilizing of previous depictions of the Void. This undecidability of forms precisely fits the "fragmentary and the chaotic 
currents of change" that literary theorist David Harvey attributes to the postmodern world (44).

The final two verses of the twelfth stanza once again contradict the "riprap" style that is the cornerstone of Snyder's earlier poetics. They read, "Dawn sun coming straight in the eye. The tooth / of a far peak called King Lear" (76-77). Ironically, the metaphoricity of the "sun coming straight in the eye" actually seems to capture the experience more effectively and precisely than any literal concrete depiction might (76). Yet, the initial image of the sun proves deceptive. In the next verse the reader discovers that the sun turns out to be reflecting off a mountain peak. The Shakespearian sounding verses reveal the precariousness of privileging the metaphorical over the literal and vice versa. Thab Hassan's postmodern condition where an individual accepts things being "misread" correlates with the incompleteness of the image of the sun that ends the portrayal of the Void. Michel Foucault captures the postmodern comfort with uncertainty that resonates in this poem when he urges us to " develop action, thought, and desires by proliferation, juxtaposition, and disjunction."' (Harvey 44). Foucault's suggestions complement the idea of 'resistance to interpretation' and also echo Snyder's breaking down of binaries.

The final two lines of Snyder's void in the twelfth stanza of "Finding the Space" incorporate metonymy with the tooth representing a ridge below the peak. The extended metaphor of the body and anthropomorphism that begins the stanza reemerges at the end of the poem in the form of the mountain peak called "King Lear." The congealing of metaphor, metonymy, and literalness dislocates the boundaries of these forms. Furthermore, Snyder's oscillating between these linguistic forms helps assure that no 
rhetorical trope or style gets privileged over another. The formerly dominant "riprap" style suddenly blends with a flourish of metaphoricity. As interpretations in the poem appear increasingly subjective, uncertainty grows. The magnification of illusory linguistic labels and "dualistic" binaries disrupts assumptions about reality and potentially strengthens a reader's developing 'resistance to interpretation.' Snyder's disruptive techniques challenge the reader by showing that "to understand non-duality as an interpretation reduces it to duality, since interpretations divide into "dualistic" categories like true/false" (Hori 303). To circumvent this weakness of ordinary perception, Snyder's idiosyncratic Buddhist poetics create the potential for a suspension of judgment. The result is a form and style that conveys a realm beyond dualisms and potentially enhances the reader's perception of the "razoredge."

\section{Nāgārjuna's Logic and Postmodernism}

The verse that epitomizes Zen's "rhetoric of disruption," as well as "resistance to interpretation," results from Snyder's emulation of Nāgārjuna's complex rendering of "emptiness." Nāgārjuna writes, "If there were to be something non-empty, there would then be something called empty. However, there is nothing that is non-empty. How could there be something empty?" (Nāgārjuna 222). According to Newman Robert Glass, author of Working Emptiness: A Study of Buddhism and Postmodern Thought, one purpose of Nāgārjuna's enigmatic thought is to apply the principle of "co-dependent arising" to the linguistic category of "emptiness." The term "co-dependent arising" refers to the idea that things and words "co-arise" in the world; on their own they are "empty" of essence or meaning. Nāgārjuna's logic works by taking advantage of the 
incomprehensibility of "non-empty" to prevent the concept of "empty" from becoming an 'absolute' category with an independent existence (50). Snyder's version of Nägārjuna's passage relating to "emptiness" reads as follows, "no flatness because no not flatness" (64). This verse utilizes the nonsensical idea of "not flatness" to disorient the concept of "flatness." Like Nāgārjuna, Snyder prevents the latter term from becoming an absolute with ultimate meaning. Paradoxically, this radical breaking down of binaries contains complex meaning, but simultaneously demonstrates that words can be thought of as "empty." Like the "emptiness" of the Void, the word "flatness" shows both a "lack of any independent essence or self in things and the interrelational dynamism that constitutes things" (Ives 2). This explanation of Buddhist ultimacy as simultaneous absence and plenitude strengthens the aesthetic of "nonduality" in "Finding the Space." Furthermore, Snyder's non-rational-but-logic-oriented phrase not only grows the 'resistance to interpretation' but also improves the possibility of a permanent dismantling of the meanings that make up the "flat"/ "not flatness" binary.

\section{Embracing 'Resistance to Interpretation'}

As I have shown throughout this thesis, Snyder's portrayal of Buddhist ultimacy is uneven and has undergone many changes. "Finding the Space" represents a compelling example of transforming the substance of Buddhist philosophy from abstract metaphysical discourse into images and ideas that improve the Buddhist aesthetics in the poem and potentially bring the reader closer to an understanding or realization of the "razoredge." Snyder's reinvigorating of old techniques and styles, and introduction of creative new strategies, dislocate commonly-held assumptions about nature and language. 
In this epilogue, I have attempted to show that his idiosyncratic Buddhist poetics strengthen the aesthetic of "nonduality" when the dismantling of preconceived images and ideas escalates. Moreover, the greater the degree to which Snyder blurs boundaries and tears down "dualistic" assumptions, the greater the potential for "resistance to interpretation' to result in a suspension of judgment or permanent rupture of meaning. 


\section{REFERENCES}

Abé, Ryūichi. "Word." Critical Terms for the Study of Buddhism. Ed. Donald S. Lopez Jr. Chicago: U of Chicago P, 2005.

Adams, Hazard, and Leroy Searle eds. Critical Theory Since 1965. Tallahassee: UP of Florida, 1986.

Aitken, Robert. A Zen Wave: Basho's Haiku and Zen. New York: Weatherhill, 1978.

Altieri, Charles. Enlarging the Temple: New Directions in American Poetry during the 1960s. London: Associated UP, 1979.

---. "The Book of the World: Robert Duncan's Poetics of Presence." Sun and Moon 1 (1976): 66-94.

Barthes, Roland. Empire of Signs. Trans. Richard Howard. New York: Hill and Wang, 1982.

Bartlett, Karen Joy. Jewels in the Net: The American Buddhist Poetics of Gary Snyder. Diss. U of Georgia: privately printed, 2000.

Bly, Robert. “The Work of Gary Snyder.” Contemporary Poets. Ed. Harold Bloom. New York: Chelsea, 1986. 357-369

Crittenden, Charles. "The Suchness of Things: in Buddhism, American Transcendentalism and Ordinary Language Philosophy." Zen in American Life and Letters. Ed. Robert S. Ellwood. $6^{\text {th }}$ ed. Malibu: Undena, 1987. 51-66. 
Dean, Tim. Gary Snyder and the American Unconscious: Inhabiting the Ground. New York: St. Martin's, 1991.

Derrida, Jacques. Of Grammatology. Trans. Gayatri Chakravorty Spivak. Baltimore: Johns Hopkins UP, 1976.

---. "Structure, Sign, and Play in the Discourse of the Human Sciences." The Critical Tradition: Classic Texts and Contemporary Trends. Ed. David H. Richter. Boston: Martin's, 1998. 877-889.

-.-. Writing and Difference. Trans. Alan Bass. Chicago: U of Chicago P, 1978.

Diener, Michael S., et al. The Shambhala Dictionary of Buddhism and Zen. Boston: Shambhala, 1991.

DiSanto, Ronald L., and Thomas J. Steele. Guidebook to Zen and the Art of Motorcycle Maintenance. New York: William Morrow, 1990.

“Ezra Pound and Fenollosa." 1997. 9 Nov. 2006 $<h t t p: / / w w w . l i b r a r y . y a l e . e d u / b e i n e c k e / o r i e n t / \bmod 3 . h t m>$.

Faas, Ekbert. Towards a New American Poetics: Essays and Interviews. Santa Barbara: Black Sparrow, 1978.

“Fenollosa, Ernest Francisco.” The Columbia Encyclopedia. $6^{\text {th }}$ ed. 2005. 9 Nov. 2006 $<$ http://www.bartleby.com/65/fe/Fenollos.html $>$.

Glass, Newman Robert. Working Emptiness: Toward a Third Reading of Emptiness in Buddhism and Postmodernism Thought. Atlanta: Scholars, 1995.

Haas, Robert. The Essential Haiku. New York: Harper, 1994.

Harvey, David. The Condition of Postmodernity. Oxford: Basil Blackwell, 1989. 
"The Heart of Prajna Paramita Sutra." Trans. Edward Conze. 2003. 9 Nov. 2006 $<$ http://www.thebigview.com/discussion/archive/index/Emptiness $>$.

Heine, Steven, and Dale S. Wright. The Koan. Oxford: Oxford UP, 2000.

Hertz, Neil. The End of the Line: Essays on Psychoanalysis and the Sublime. New York: Columbia UP, 1985.

Hori, G. Victor Sōgen. "Koan and Kensho in the Rinzai Zen Curriculum." The Koan. Ed. Steven Heine and Dale S. Wright. Oxford: Oxford UP, 2000. 280-315.

Irwin, John T. American Hieroglyphics. New Haven: Yale UP, 1980.

Ives, Christopher. Zen Awakening and Society. Honolulu: U of Hawaii P, 1992.

Jakobson, Nolan Pliny. Understanding Buddhism. Carbondale: Southern Illinois UP, 1986.

Jones, A.R. "Imagism: A Unity of Gesture.” American Poetry. Ed. Irvin Ehrenpreis. New York: Martin's, 1965. 115-134.

Kant, Immanuel. Critique of Judgment. Trans. J.H. Bernard. New York: Hafner, 1951.

Kenner, Hugh. The Pound Era. Berkeley: U of California P, 1971.

Kern, Robert. "Clearing the Ground: Gary Snyder and the Modernist Imperative." Criticism 19 (1977): 158-177.

Kerouac, Jack. The Dharma Bums. New York: Penguin, 1976.

Lacan, Jacques. "The Agency of the Letter in the Unconscious." The Critical

Tradition: Classic Texts and Contemporary Trends. Ed. David H. Richter. Boston: Martin's, 1998. 1044-1065. 
Lin, Yao-fu. "“The Mountains Are Your Mind'; Orientalism in the Poetry of Gary Snyder." Tamkang Review 6 2-7:i (1975) 357-391.

Loy, David R. "The Deconstruction of Buddhism.” 1992. 9 Nov. 2006. $<h t t p: / / w w w . c c b s . n t u . e d u . t w . f u l l t e x t / j r-e n g / l o y 10 . h t m>$.

Magliosa, Robert. Derrida on the Mend. West Lafayette: Purdue UP, 1984.

Martin, Julia. "The Pattern Which Connects: Metaphor in Gary Snyder's Later Poetry." Western American Literature 22.2 (1987) 99-123.

Mitgutsch, Waltraud. "Gary Snyder's Poetry: A Fusion of East and West.” Essays in Honour of Erwin Sturzl on His Sixtieth Birthday. Ed. James Hogg. Vol. 2, $10^{\text {th }}$ ed. Salzburg, Austria: Salzburg U, 1980.424-454.

Molesworth, Charles. Gary Snyder's Vision: Poetry and the Real Work. Columbia: U of Missouri P, 1983.

Murphy, Patrick. Understanding Gary Snyder. Columbia: U of South Carolina P, 1992. Nāgārjuna. Nāgārjuna: The Philosophy of the Middle Way. Trans. David J. Kalupahana. Albany: State University of New York P, 1986.

Norton, Jody. "The Importance of Nothing: Absence and Its Origins in the Poetry of Gary Snyder." Critical Essays on Gary Snyder. Ed. Patrick Murphy. Boston: G. K. Hall, 1991.

O’Conner, Michael. “Literary Modernism.” Milliken University. Apr. 2000. 9 Nov. 2006. $<$ http://www.millikin.edu/aci/crow/basics/modernism.html>.

Oelschlaeger, Max. The idea of Wilderness: From Prehistory to the Age of Ecology. New Haven: Yale UP, 1991. 
Okada, Roy Kazuaki. Zen and the Poetry of Gary Snyder. Diss. U of Louisville, 1974. Ann Arbor: privately printed, 1974.

Parkinson, Thomas. "The Poetry of Gary Snyder." The Southern Review. 4 (1968): 616632.

Paul, Sherman. Repossessing and Renewing: Essays in the Green Tradition. Baton Rouge: Louisiana State UP, 1976.

Seele, Michael “Eastern Influence.” Chronicle 5.7 (1996). 17 Nov. 2006. $<$ http://www.bc.edu/bc_org/rvp/pubaf/chronicle/v5/N27/kern.html>.

Selby, Nick. "Poem as Work-Place: Gary Snyder's Ecological Poetics." Sycamore 1.4 (1997). 8 Nov. $2006<$ http://www.english.uiuc.edu/maps/poets/s_z/snyder/selby.htm>.

Snyder, Gary. The Back Country. New York: New Directions, 1968.

---. Earth House Hold. New York: New Directions, 1969.

---. The Gary Snyder Reader: Prose, Poetry, and Translations 1952-1998. Washington D.C.: Counterpoint, 1999.

---. Mountains and Rivers Without End. Washington D.C.: Counterpoint, 1996.

---. Myths and Texts. New York: Totem, 1960.

---. The Old Ways. San Francisco: City Lights, 1977.

---. A Place in Space: Ethics, Aesthetics, and Watersheds. New York: Counterpoint, 1995.

---. The Real Work: Interviews \& Talks 1964-1979. New York: New Directions, 1980.

---. Regarding Wave. New York: New Directions, 1970.

---. Riprap and Cold Mountain Poems. Washington D.C.: Shoemaker \& Hoard, 1965.

---. Turtle Island. New York: New Directions, 1974. 
Soulsby, Marlene Pilarcik. "Zen and the Way of Reading Hermann Hesse's Das Glasperlenspiel.” Studia Mystica. 11.1 (1988): 3-17.

Steuding, Bob. Gary Snyder. Boston: Twayne, 1976.

Tanahashi, Kazuaki, ed. Moon in a Dewdrop: Writings of Zen Master Dōgen. San Francisco: North Point Press, 1985.

Thoreau, Henry David. Walden and Other Writings by Henry David Thoreau. Ed. Joseph Wood Krutch. New York: Bantam,1981.

Trumbull, Charles. “The American Haiku Movement." Modern Haiku. 37.1 (2006). 9 Nov. 2006. <http://www.modernhaiku.org/essays/AmHaikuMovement2.html>. Watts, Alan. The Way of Zen. New York: Random, 1957.

Wright, Dale S. Philosophical Meditations on Zen Buddhism. Cambridge: Cambridge UP, 1998.

Wright, James. "The Work of Gary Snyder." Contemporary Poets. Ed. Harold Bloom. New York: Chelsea, 1986.

Yip, Wai-lim. Diffusion of Distances. Berkeley: U of California P, 1993.

"Zen." Merriam-Webster Online. 2006. 9 Nov. 2006.

$<$ <ttp://www.m-w.com/dictionary/zen>. 


\section{CURRICULUM VITAE}

NAME: $\quad$ David Gerhardt Thimme

ADDRESS: $\quad 7524$ Rockingham Road

Prospect, KY 40059

DOB: $\quad$ San Antonio, Texas - June 24, 1970

EDUCATION: B.S., Business Management

Bradley University, 1993 